NASA Technical Memorandum 106181

AIAA-93-2043

\title{
An Analytical Study of Dilution Jet Mixing in a Cylindrical Duct
}

V.L. Oechsle and H.C. Mongia

General Motors Corporation

Indianapolis, Indiana

and

J.D. Holdeman

Lewis Research Center

Cleveland, Ohio

Prepared for the

29th Joint Propulsion Conference and Exhibit

cosponsored by the AIAA, SAE, ASME, and ASEE

Monterey, California, June 28-30, 1993 


\title{
AN ANALYTICAL STUDY OF JET MIXING IN A CYLINDRICAL DUCT
}

\author{
V. L. Oechsle* and H. C. Mongia* \\ Allison Gas Turbine Division \\ General Motors Corporation \\ Indianapolis, In 46206 \\ J. D. Holdeman $\$$ \\ National Aeronautics and Space Administration \\ Lewis Research Center \\ Cleveland. $\mathrm{OH} 44135$
}

\begin{abstract}
$\underline{\text { Abstract }}$
The mixing performance in a mixing section of a rich burn/quick mix/lean burn (RQL) combustor has been calculated using a 3-D numerical model in a non-reacting environment. The numerically calculated results have been compared with the measured data reported by Hatch, Sowa, Samuelsen, and Holdeman, 1992. The numerical 3-D temperature fields qualitatively agree with the experimental data. Also the development of the mixing flow and temperature non-uniformity trends throughout the mixing section for the numerically calculated results quantitatively agree with the measured data. The numerical model predicts less mixing and enhances the temperature gradients as compared to the measured data for the cases reported by Hatch et al. (1992) which include circular and slot orifice shapes (with different slant angles and aspect ratios). The predicted and measured results generally agree in the selection of the slanted slot orifice configuration yielding the best overall mixing performance (based on temperature uniformity) of all the configurations analyzed herein.
\end{abstract}

\section{Nomenclature}

$A_{m} \quad=$ duct crossectional area, also $A_{t o t}, m^{2}$

$\mathrm{ACd}=$ effective orifice area, $\mathrm{m}^{2}$

$\mathrm{AR}=$ area ratio (jet/mainstream) $=\mathrm{A}_{\mathrm{j}} / \mathrm{A}_{\mathrm{m}}=\mathrm{ACd} / \mathrm{A}_{\mathrm{m}}$

AMIX = area weighted overall temperature deviation from Teq, Eq 3

AHOT $=$ area weighted temperature deviation above Teq. Eq 4

ACOLD = area weighted temperature deviation below Teq. Eq 5

DR = density ratio (jet/mainstream)

* AIAA member

$\S$ Senior Research Engineer, AIAA Associate Fellow

Copyright 91992 by the Americ an Institute of Aeronautics and Astronautics, Inc. No copyright is asserted in the United States under Title 17. U.S. Code. The U.S. Government has the royalty-free licence to exercise all rights under the conpyright clained herein for Govemment purposes. All other rights are reserved by the copyright owner.

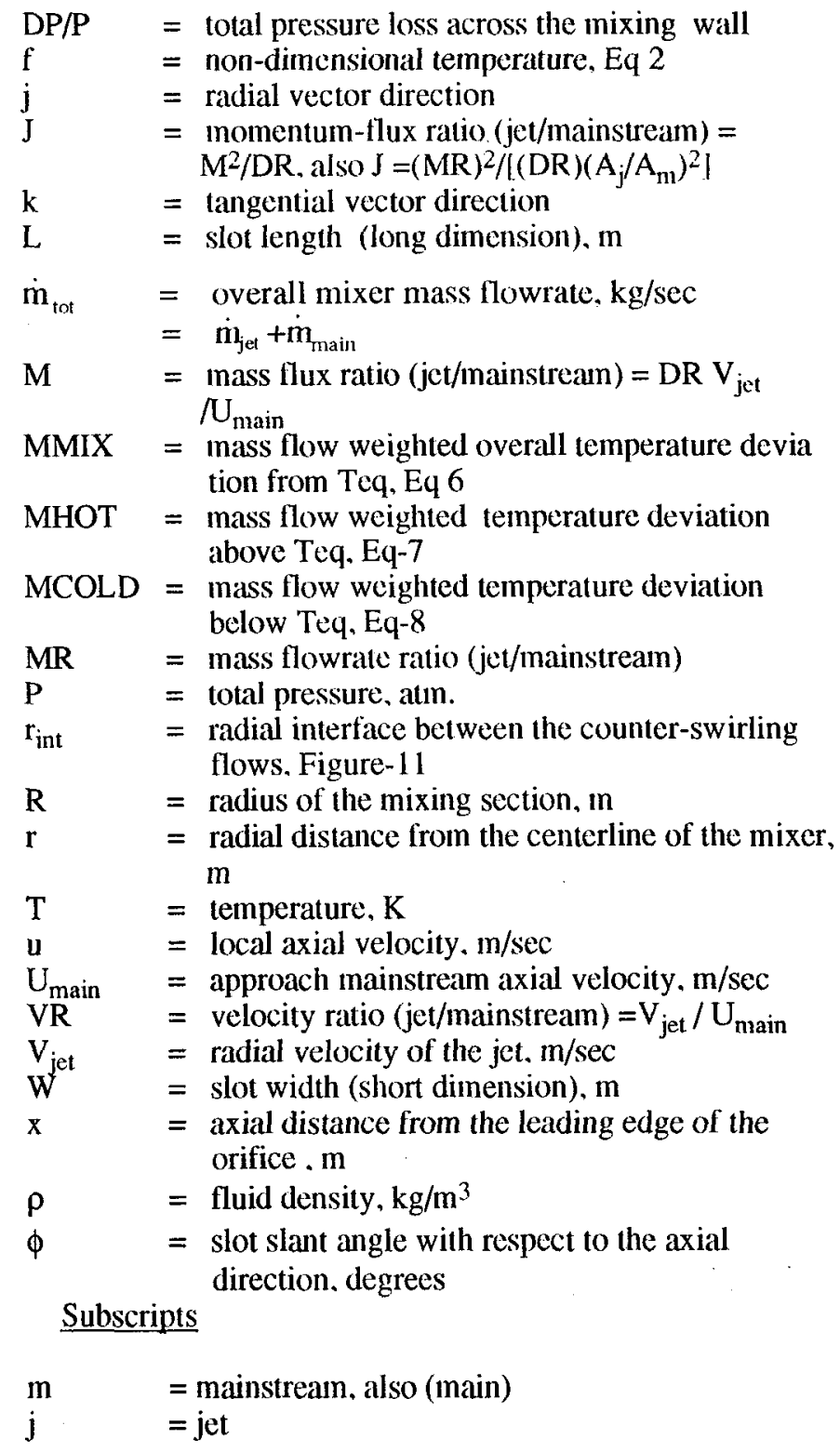




\section{Introduction}

Advanced highly fuel-efficient commercial turbo propulsion gas turbines pose a number of design challenges for combustion system including durability, aerothermal performance, wide operability range, and exhaust emissions. Gas turbine combustion systems in current use employ a single stage combustion zone which has been optimized to produce low exhaust emissions of carbon monoxide, and unburned hydrocarbons at idle and near-idle operating conditions. Exhaust smoke below the threshold of plume visibility throughout the engine operation range has also been maintained without adversely affecting engine starting, stability, and relight requirement. Moderate reductions in $\mathrm{NO}_{\mathrm{x}}$ emissions (up to $30 \%$ ) have been achieved in single-combustion- zone combustors by reducing unmixedness and combustion zone residence time. Further reductions in high-power $\mathrm{NO}_{\mathrm{x}}$ emissions (c.g. up to $50 \%$ from state-of-the-art levels) would require design and development of two-stage combustion concepts, namely, radially or axially staged combustion. These types of combustion systems are currently under development.

In order to achieve more demanding ( 70 to $90 \%$ ) $\mathrm{NO}_{\mathrm{x}}$ reduction goals of the advanced turbine engines which will have considerably higher overall pressure ratios and turbine rotor inlet temperatures, significant advances are needed in the design and development of combustion systems employing multi-staging concepts including lean premix (LPP) and rich burn/quick mix/lean burn (RQL) (Shaw, 1991). The RQL concept studied in-depth by Rizk and Mongia (e.g. Rizk and Mongia, $1990 ; 1991 ; 1993$ ) appears to have a number of advantages over other competing ultra-low $\mathrm{NO}_{\mathrm{x}}$ concepts provided we can significantly reduce the $\mathrm{NO}_{\mathrm{x}}$ formation by enhancing the mixing in the transition from rich to lean-side combustion. An experimental and analytical research effort under the sponworship of NASA Lewis Research Center (e.g. Smith, Talpallikar, and Holdeman, 1991: Talpallikar et al., 1991: Vranos et al.. 1991; Hatch et al., 1992, Bain, Smith, and Holdeman, 1992; Liscinsky et at., 1992; : Oechsle, Mongia, and Holdeman, 1992; Kroll et al., 1993; Liscinsky, Vranos, and Lohmann, 1993) is underway to study and identify the critical design and flow parameters affecting the mixing effectiveness.

The 3-D analytical technique can be an advantageous tool since a large number of configurations can be easily modeled with dense computational grids in order to resolve the typical complex flow structure present in the jet entry into a crossflow media. However due to the modeling assumptions and experimental uncertainty, variations in the numerically calculated resuits as compared to the measured data have been observed. It is therefore necessary to quantify the difference between the measured and numerically calculated mixedness results for a jet in a crossflow before further utilizing the analytical model as a configuration screemin tool. In this investigation, the mixing effectiveness of a jet in a crossflow is numerically analyzed using a 3-D analytica' code. Eighteen different configurations were analyze which included a) circular orifices at three jet-to-manstrean. momentum-flux ratio (J) conditions, and b) slots with aspect ratios L/W of 4 and 8 with different slant angles between 0 and $90^{\circ}$, and at varying $J$ conditions. The procedure used ti model the geometric configurations was similar to that used by Oechsle. Mongia, and Holdeman, 1992. In this study however, the numerically calculated temperature field anc temperature non-uniformity results werc compared wit measured data obtained by Hatch et al. (1992), and the difference has been quantified by measuring the variation of the temperature distribution with respect to the equilibriur: temperature.

\section{Mathematical Model}

A production 3-D combustor code (COM-3D), solves the turbulent reacting flow transport equations using the SIMPLE algorithm of Patankar and Spalding (Patankar. 1980). Thi program simulates turbulence by the two-equation $k-\varepsilon$ mode: (Launder and Spalding. 1974), and combustion following vaporization is determined by a four-step chemical reaction model based on Arrhenius and eddy breakup concepts (Mon. gia and Reynolds, 1979). The transport equations for ali dependent variables are of the following form as shown in Eq-1:

$$
\operatorname{div}\left[\rho u \xi-\left(\mu_{\mathrm{eff}} / \mathrm{P}_{\mathrm{r}}\right) \operatorname{grad}(\xi)\right]=\mathrm{S}_{\xi}
$$

where $\rho_{\mathrm{r}}$ is the mixture density, $u$ is the velocity, $\mu_{\mathrm{eff}}$ is the effective turbulent viscosity, $P_{r}$ is the effective Prandı//Schmidt number, and $S_{\xi}$ is the source term for the variable $\xi$. The following variables are computed by the three-dimensional code: 1) axial, radial. and swirl velocity components; 2) specific enthalpy and temperature; 3) turbulence kinetic energy and dissipation rate; 4) unburned fue and composite fuel fraction; and 5) fuel spray trajectory anc evaporation rate.

The computational effort is significantly reduced by modeling a sector of the mixing section comprising a single orifice Therefore, the shape of the sector was dependent on the number of orifices equally spaced in the circumferential direction. It should be noted that there are 8 orifices in all configurations, so the computational domain is a 45 degree sector. Periodic boundary conditions were applied in the circumferential direction. These conditions were necessary for the mixing configurations generating swirl during the mixing process generally characteristic of the slanted slot orifice configurations. No-slip and adiabatic boundary conditions were applied at the outer wall defining the inside wall of the mixing section. The computation at the center axis was extrapolated based on the nearest surrounding values due to its singularity. No-gradient and slip boundary 
conditions were applied at the center axis. Fully developed profiles (no axial gradients) were assumed at the exit boundary condition.

\section{Geometric Configuration}

In this study, the mixing section was modeled as a constant diameter cylindrical "can" with a single row of equally spaced orifices. The outer wall diameter is $76 \mathrm{~mm}$ ( 3 inch) and the axial length of the mixing section extended from $x / R=-1.5$ to $x / R=6$ where $x$ is referenced from the leading edge of the orifice. Sufficient axial distance was provided both upstream and downstream of the orifice to prevent any entry or exit effects from modifying the flow structure in the computational domain of interest which is $0<\mathrm{x} / \mathrm{R}<2$. The computational grid of the domain typically comprised of 50.000 to 80,000 control volumes. The grid was typically denser near the orifice and near the outer wall to resolve the high velocity and temperature gradients resulting from the inlet of the crosstlow jet. An orthogonal view of the computational grid is shown in Figure-1. The grid was also configured to allow smooth progressive volume change between adjacent control volumes to help speed up the convergence of the solution.

The geometric configurations of the jet orifices is also shown in Figure-1. Two different general shapes of orifices were modeled: round holes and slanted slots of $4: 1$ and $8: 1$ aspect ratios, and a total matrix of 18 different configurations were analyzed. Also, it should be noted that the $90^{\circ}$ sector shown in the following temperature plots always includes orifice centers at $22.5^{\circ}$ and $67.5^{\circ}$. The description of the configurations is tabulated in Table- 1 and shown graphically in Figure-2. Twelve of the configurations shown in Table-1 duplicate the initial conditions reported in Hatch, Sowa, Samuelsen, and Holdeman, 1992). The configurations for which the measured data are not reported by Hatch et al. are configurations $4,5,11,12,14$, and 15 . The blockage parameter tabulated in Table 1 is defined as the circumferential projection of the orifice divided by the spacing between the orifice centers. Similarly the orifice trailing edge (T.E.) $x / R$ is defined as the axial projection of the orifice divided by the mixer radius $R$. As shown in the aforementioned experimental study, the matrix of analyzed configurations is such that for a specific orifice shape, the increase in $J$ does not change the MR. This was accomplished by reducing the orifice effective area $(A C d)$ to increase the $I$ value while keeping the MR constant (see Table-1). The model of the orifice perimeter was performed by a stair-stepping approximation since COM-3D is not a body conforming code. Therefore, to increase the modeling accuracy, the orifice was typically defined with between 100 and 200 control volumes. The orifice ACd was modeled to within less than $1 \%$ deviation.

The mixing section was modeled at atmospheric pressure. The mainstream flow and jet flow conditions are show in Table-1. The MR. mainstream flowrate, and jet temperature were maintained constant throughout the parametric study. The variation in $J$ was chosen as a representative range for typical gas turbine combustion systems. The mainstream flow at the inlet of the modeled mixing region was characterized by a uniform temperature and axial plug flow velocity profiles in the radial-circumferential plane. The air jet llow was characterized by a radial, uniform flow across the orifice effective area. The assumption of uniform mass injection/area is applied in the mathematical model in all the analyzed configurations. The turbulence kinetic energy of the mainstream and jet flows were $0.3 \%$ of the square of the mean velocities. The turbulence length scales of the mainstream flow were $2 \%$ of the can diameter, and the turbulence length scale of the jet was of the order of the orifice diameter. The inlet conditions for all orifices in the mixing section were equal to create a symmetrical input condition about the circumferential direction which was necessary for the sector analysis. The operating pressure and temperature range was chosen to duplicate the experimental setup.

A typical numerical solution took about 250 itcrations for full convergence with overall mass flow residuals of $0.05 \%$ of the total mixing section mass flowrate. All solutions were obtained using the Cray Y-MP and a typically converged solution took about 1 to 1.5 hrs of CPU time.

\section{Results and Discussion}

The mixing performance for all configurations analyzed in this study were ultimately cvaluated at $x / R=1$. It is however recognized that the mixing performance throughout the entire mixing section $0<\mathrm{x} / \mathrm{R}<1$ should also be considered since complex structures are present in the flow field especially near the entry of the jet. The numerically calculated results were obtained using a grid with about 1200 computational nodes in each radial-tangential plane ( $45^{\circ}$ sector). Similarly the grid size of the expcrimental data is 50 points per radial-tangential plane $\left(90^{\circ}\right.$ sector) therefore in order to appropriately weigh the numerically calculated results. only the calculated results at the measured locations were used for the comparison.

Two different methods were used to present the numerical results and compare them with their respective measured data:

1) the results were analyzed qualitatively by visual observation of the temperature and velocity field solutions. The normalized temperature plots presented in this paper describe a domain from $x / R=0.08$ to $x / R=1$. In all the temperature plots, the air flows from left to right. The temperature results are presented as normalized values with respect to the overall differential between the mainstream flow and the jet flow inlet temperatures: This normalized temperature is defined in Eq-2. 


$$
f=\frac{T_{j k}-T_{j e t}}{T_{\text {main }}-T_{j e t}}
$$

The value of $f$ varies from 0 to 1 . where 0 is the value of the unmixed jet and 1 is the value of the mainstream flow. Note that $\mathrm{f}=1-\theta$. where $\theta$ is as defined previously (Holdeman. 1991) and used elsewhere also. The value of the equilibrium temperature was calculated in a purely adiabatic system at any location downstream of the jet injection. The equilibrium temperature was also normalized in the same manner as the local temperature. Five different planes are displayed in each plot corresponding to the planes in the radial-tangential direction at $x / R$ of $0.08,0.25,0.5,0.75$, and 1 . Two adjacent sectors are plotted in each plane to show the continuity in the region between the orifices. Note that these planes were specifically chosen since these are the actual measured planes. Each of the normalized temperature contour plots of the configurations with corresponding measurements include the following:

a) the complete numerically calculated normalized temperature distribution

b) the numerically calculated results at the measured locations

c) plot of the measured results (Hatch, Sowa, Samuelsen, and Holdeman 1992.)

2) The mixing performance of the mixing section was also evaluated by using statistical area weighted deviation. The smallest deviation indicates the best mixing configuration. Three different parameters (mixing deviations) AMIX. AHOT. and ACOLD are described in Eq-3 through Eq-5. Note that AMIX also equals square root of the sum of the squared values of both AHOT and ACOLD. It is also important to note that the definitions in Eq-3 through Eq-5 do not correct the mixing non-uniformity for the bias introduced in the region of the section where the air is actively being injected through the orifice. This is accepted since the comparison between the measured and numerically calculated results is only performed at $x / R=1$ which is downstream of the trailing edge of the orifice. The numerically calculated and measured area-weighted non-uniformity results are shown in Table-2.

$$
\begin{aligned}
& \text { AMIX }=\left[\frac{1}{A_{\text {tot }}} \sum_{j \mathrm{k}} \mathrm{A}_{\mathrm{jk}}\left[\frac{\mathrm{T}_{\mathrm{jk}}-\mathrm{T}_{\mathrm{eq}}}{\mathrm{T}_{\text {main }}-\mathrm{T}_{\mathrm{ket}}}\right]^{2}\right]^{1 / 2} \\
& \text { AHOT }=\left[\frac{1}{\mathrm{~A}_{\text {tot }}} \sum_{\mathrm{jk}} \mathrm{A}_{\mathrm{jk}}\left[\frac{\mathrm{T}_{\mathrm{jk}}-\mathrm{T}_{\mathrm{eq}}}{\mathrm{T}_{\text {main }}-\mathrm{T}_{\mathrm{ket}}}\right]^{2}\right]^{1 / 2} \text { for } \mathrm{T}_{\mathrm{jk}}>\mathrm{T}_{\mathrm{eq}}
\end{aligned}
$$

$$
\operatorname{ACOLD}=\left[\frac{1}{A_{\text {tot }}} \sum_{j \mathrm{k}} \mathrm{A}_{\mathrm{jk}}\left[\frac{\mathrm{T}_{\mathrm{jk}}-\mathrm{T}_{\mathrm{eq}}}{\mathrm{T}_{\text {main }}-\mathrm{T}_{\mathrm{jet}}}\right]^{2}\right]^{1 / 2} \text { for } \mathrm{T}_{\mathrm{jk}}<\mathrm{T}_{\mathrm{eq}}
$$

In addition, the area weighted statistical deviations were also compared with a mass flow weighted parameters as definec in Eq-6 through Eq-8. The MMIX value also equals the square root of the sum of the squared values of both MHOT and MCOLD. Note that these parameters are essentially the same as the area weighted parameters with the density anc velocity weighting terms added.

$$
\begin{aligned}
& \text { MMIX }=\left[\frac{1}{\dot{m}_{\text {tot }}} \sum_{\mathrm{jk}} \mathrm{A}_{\mathrm{jk}} \rho_{\mathrm{jk}} \mathrm{u}_{\mathrm{jk}}\left[\frac{\mathrm{T}_{\mathrm{jk}}-\mathrm{T}_{\mathrm{eq}}}{\mathrm{T}_{\text {main }}-\mathrm{T}_{\mathrm{jet}}}\right]^{2}\right]^{1 / 2} \\
& \text { MHOT }=\left[\frac{1}{\dot{\mathrm{m}}_{\mathrm{tot}}} \sum_{\mathrm{jk}} \mathrm{A}_{\mathrm{jk}} \rho_{\mathrm{jk}} \mathrm{u}_{\mathrm{jk}}\left[\frac{\mathrm{T}_{\mathrm{jk}}-\mathrm{T}_{\mathrm{eq}}}{\mathrm{T}_{\text {main }}-\mathrm{T}_{\mathrm{jet}}}\right]^{2}\right]^{1 / 2} \text { for } \mathrm{T}_{\mathrm{jk}}>\mathrm{T}_{\mathrm{eq}} \\
& \text { MCOLD }=\left[\frac{1}{\dot{\mathrm{m}}_{\text {tot }}} \sum_{\mathrm{jk}} \mathrm{A}_{\mathrm{jk}} \rho_{\mathrm{jk}} \mathrm{u}_{\mathrm{jk}}\left[\frac{\mathrm{T}_{\mathrm{jk}}-\mathrm{T}_{\mathrm{eq}}}{\mathrm{T}_{\mathrm{masin}}-\mathrm{T}_{\mathrm{jet}}}\right]^{2}\right]^{1 / 2} \text { for } \mathrm{T}_{\mathrm{jk}}<\mathrm{T}_{\mathrm{eq}}
\end{aligned}
$$

The results in this paper are presented in the following manner:

a) effect of momentum flux ratio (J) on mixing,

b) effect of orifice configuration on mixing,

c) effect of the slot slant angle ( $\phi)$ on mixing, and

d) comparison of the mixing trends obtained with the numerically calculated and measured results.

\section{Effect of Momentum Flux Ratio $(\mathrm{J})$}

Round holes. The mixing uniformity of all three round hole configurations are shown in Figures-3, 4, 5, and 6a for increasing $\mathrm{J}$ of 25.52. and 80 . It is important to note that the calculated values at the measured locations are essential to make a valid comparison between the numerically calculated and measured results. Since each quadrant in the measured data contains 50 points per plane, it will not resolve the large gradients in the temperature distribution usually present near the jet entrance. Therefore, in order to compare the measured and the numerically calculated results, the calculated data was linearly interpolated at the actual measured focations. The comparison of the experimentally calculated and measured results for these configurations are also shown in Figure-7a. The lowest possible AMIX. AHOT, and ACOLD yields the best temeprature uniformity. The bar charts shown in Figure-7 depict the absolute value of the difference 
between the mixing non-uniformity of the measured and numerically modeled statistical parameters. It is evident from the temperature plots that the increase of $J$ beyond the value of 25 produces over-penetration. The mixing non-uniformity values AMIX, and AHOT both indicate a deteriorated performance with both the measured and calculated results which is in agreement with the expected results. However, the relative comparison of the numerical and experimental results indicate that a better comparison is evident with increasing $J$ as shown in Figure-7a (showing the decreasing relative difference between both values with increasing $J$ ). As previously reported in Hatch et al. (1992), the increase in J produced over-penetration which generally degraded the mixing uniformity. Similarly, the numerically calculated results also indicate some deterioration in mixing uniformity; however. this deterioration is smaller with increasing $J$ (Figure-6a). There appears to be a slight improvement in the numerically calculated mixing uniformity results at $J=80$ due to the strong recirculation in the axial direction produced by the impingement of opposing jets in the mixing section. The recirculation produces some additional jet-to-mainstream flow interaction and additional mixing therefore reducing the effect hot mainstream air flow behind the wake of the jet. This effect appears to be diminished in the measured results since jet peneiration was lower as compared to the calculated results at the same $\mathrm{J}$; and therefore. the jet impingement recirculation is also smaller in the measured case. Note that the optimum jet penetration as calculated in Holdeman (1991) for a nominal $\mathrm{J}=25$ is 9 holes/row as calculated in $\mathrm{Eq}-9$ where $n$ is the number of orifices and $C=2.50$, and these results seem to correlate well with the round jet results shown in Figure-3.

$$
\mathrm{n}=\frac{\pi \sqrt{2 J}}{\mathrm{C}}
$$

Slot aspect ratio $L / W=4$, with $\phi=45^{\circ}$. The $\operatorname{mix}$ ing non-uniformity and normalized temperature profile plots for the $45^{\circ}$ slanted slot with $L / W=4$ are shown in Figures- $6 \mathrm{~b}, 7 \mathrm{~b}$, 8,9, and 10 . A significant difference between the measured and numerically modeled results are observed for the $L / W=4$ slots as $J$ is increased from 25 to 80 (Figure-7b). As $J$ is increased, the swirl increases in the flow field. The swirl is a consequence of the jet flow acting like an effective turning vane which causes the mainstream flow to swirl in the circumferential direction. Since there is no tangential velocity component to either the approach flow or jet, the induced swirl is actually a double counter-swirling flow such as to conserve the angular momentum of the entire system. The effect of this double recirculation shown in Oechsle, Mongia, and Holdeman (1992), can have a detrimental effect on the mixing uniformity in the numerical model since the mainstream flow becomes trapped in the wake of the jet and remains in the outer section of the mixer as the flow proceeds downstream. This creates a radially stratified temperature profile with hotter gas towards the outer wall of the mixing section. Due to the counter-swirling flow in the mixer downstream of the orifice, the hot gas has little interaction with the cooler jet flow (only if the jet significantly penetrates into the inner recirculation core) since the stagnation region between the two counter-swirling flows produces an effective "barrier" to prevent significant mass flow transport in the radial direction. This effect appears to have a significant influence in the results shown in Figures-6b and $7 \mathrm{~b}$. As $J$ is increased from 25 to 52 , the radial temperature stratification becomes more significant in the numerically calculated results as compared to the measured results. and this appears to have a direct effect on the mixing non-uniformity since the hotter gas resides towards the outer section of the mixer. In the numerically calculated results, the increase in J from 25 to 80 has a $10 \%$ decrease in the interface $\left(r_{\text {int }}\right.$ ) between the counter-swirling flows as shown in Figure- 11 but the increase in jet penetration, as shown in Eq-9, is proportional to the $\mathrm{VJ}$, and therefore jet penetration rather than $r_{\text {int }}$ is more sensitive to $\mathrm{J}$. It is therefore apparent that the numerically calculated results showing these temperature stratifications will deviate more compared to the measurements for orifice configurations with $\mathrm{J}=52$ as shown in Figure-7b. As $\mathrm{J}$ is further increased to 80 , the jet impingement recirculation produced by opposing jets aid the mixing the numerical results and therefore shows a slight improvement in mixing.

Slot aspect ratio $L / W=8$, with $\phi=45^{\circ}$. The mixing uniformity and temperature profile plots for the $45^{\circ}$ slanted slot with $\mathrm{L} / \mathrm{W}=8$ for increasing J from 25 to 80 are shown in Figures-6c, $7 \mathrm{c}, 12,13$, and 14. The penetration of the jet of the $\mathrm{L} / \mathrm{W}=8$ slot is relatively smaller as compared to the $\mathrm{L} / \mathrm{W}=4$ slots at the same $\mathrm{J}$ condition due to the long and narrow orifice configuration; and therefore, this is the only orifice configuration shape (of those analyzed herein) that approaches optimum penetration with increasing $J$. In addition, the variation of jet penetration with $J$ appears to be weaker as compared to the $\mathrm{L} / \mathrm{W}=4$ slots or circular holes. The numerically calculated results indicate a slight degradation in the mixing non-uniformity with the increase in $J$ (Figure-6c). Large differences in the comparison between the measured and calculated results are shown in Figure- $7 \mathrm{c}$. Of the cases analyzed numerically, none showed jet impingement recirculation for the range of $J$ of 25 to 80 and therefore no additional mixing benefit was derived as $J$ is increased to 80 as shown previously for the circular holes and $L / W=4$ slots. Considering that the mixing development throughout the mixer downstream of $x / R=0.5$ is small, the deviation between the calculations and measurements will increase. especially if the measured results show significant mixing progress beyond $x / R=0.5$ as shown in Figures $-12,13$, and 14 .

\section{Effect of Orifice Configuration}

Considering that the design parameter J will most likely be constant for a given combustion liner design, it is therefore valuable to compare the mixing non-uniformity results for several orifice configurations at constant $J$. The round holes, $L / W=4$ slot, and $L / W=8$ slot orifice configurations are compared at $J=25,52$, and 80 as shown in Figure- 15 for the 
numerically calculated results. The temperature profiles corresponding to Figures-15a and 16 a are shown in Figures-3, 8, and 12 . The temperature profiles corresponding to Figures $-15 \mathrm{~b}$ and $16 \mathrm{~b}$ are shown in Figures 4,9 , and 13 . Similarly, the temperature profiles corresponding to Figures $-15 \mathrm{c}$ and $16 \mathrm{c}$ are shown in Figures-5, 10, and 14. These results almost exclusively show the $\mathrm{L} / \mathrm{W}=8$ slot as the best mixing configuration for all $J$ values due to the shallow jet penetration and ability to mix well in the wake behind the orifice. It is important to note that the effect of jet under-penetration (produced by the $\mathrm{L} / \mathrm{W}=8$ slot) creates enhanced mixing towards the outer wall of the mixer at expense of a slightly hotter core (Figure-12b) as compared to the round and $L / W=4$ slot results (Figures -3 and 8 ). The difference between the numerically calculated results and measured results show the large expected differences at $\phi=45^{\circ}$ as mentioned previously especially for $\mathrm{J}=52$ as shown in Figure- 16.

\section{Effect of Slot Slant Angle (申)}

The effect of the increase in slot slant angle on the mixing uniformity is shown in Figures-17, 18, 19,20, and 21 for the $\mathrm{L} / \mathrm{W}=4$ slot at slant angles of $0^{\circ}, 22.5^{\circ}, 45^{\circ}$, and $67.5^{\circ}$ respectively for $J=52$. The difference in the mixing non-uniformity between the numerically calculated and measured results is shown in Figure-21c. As shown previously in Oechsle, Mongia, and Holdeman (1992). the increase in slot slant angle increases the induced flow counter-recirculation in the mixer which generally radially stratifies the temperature distribution (hotter towards the outer wall). This phenomena was mostly observed for the slant angle producing the strongest swirl $\left(\phi=45^{\circ}\right)$. It is also not surprising that the numerically calculated mixing non-uniformity at $\phi=45^{\circ}$ is the highest as shown in Figure-21a. As $\phi$ is increased to $67.5^{\circ}$, the jet penetration decreases sufficiently to allow the cold jet to mix with the hot gas trapped behind the orifice. The decrease in jet penetration with increased $\phi$ beyond $45^{\circ}$ is mainly caused by the increase in jet blockage, as mentioned previously in Oechsle, Mongia, and Holdeman (1992). The enhanced mixing for $\phi=67.5^{\circ}$ is shown in Figure-21a. This effect appears to be a key element in producing a well mixed numerically calculated flow field. The measured flow field however, is generally well mixed for the slanted slot configurations with $\phi$ from $22.5^{\circ}$ to $67.5^{\circ}$ and no significant change in performance was shown at $\mathrm{J}=52$ (Figure-21b).

The effect of $\phi$ on the comparison of the numerically calculated and measured mixing non-uniformity for $\mathrm{J}=25$ and 80 are not reported herein due to the lack of measured data reported, however, the numerical results were obtained at several $\phi$ for the $\mathrm{L} / \mathrm{W}=4$ slot at $\mathrm{J}=25$ and 80 (Figure-2). At $J=25$, the effect of mixing non-uniformity for a variation of $\phi$ from 0 to $45^{\circ}$ is shown in Figures- 22 and $23 \mathrm{a}$. It should be noted that at the low $\mathrm{J}$ condition, the $67.5^{\circ}$ and $90^{\circ}$ slots were not analyzed due to phisical constraints since the orifices wi.. overlap each other. The results indicate small changes similar to those reported by Oechsle. Mongia, and Holdema (1992). At $J=80$, the range in $\phi$ from $0^{\circ}$ to $90^{\circ}$ (Iransversel: oriented) for $\mathrm{L} / \mathrm{W}=4$ slots are shown in Figures-23c and 24 respectively. The results are also similar to those reported in Oechsle. Mongia. and Holdeman (1992). The improvemen in mixing for $\phi$ above $45^{\circ}$ is caused the same effect a. explained for the $J=52$ results (Figure-23b).

Comparison between the mixing trends for the numerically calculated and measured results.

In general, the numerically calculated results follow the measured trends throughout the mixing section domain as seen in the Figures-25, 26, 27. and 28. It is evident from al the previously shown temperature plots that significan. temperature gradients are still present in the numerically calculated results at $x / R=1$. This observation is expected given the nature of the production elliptic code which hat been observed and reported significantly in the past.

Reiterating that lowest possible AMIX, AHOT, ACOLD MMIX, MHOT, and MCOLD values depict best mixing, thi results indicate similar trends for the measured as well as for the numerically calculated results in the development of the mixing flow field. However the temperature gradients in th: calculations appear not to significantly change downstrean of $\mathrm{x} / \mathrm{R}=0.5$ indicating very little mass or thermal transport in the radial and circumferential directions downstream $o^{5}$ $x / R=0.5$. This was not the case with the measured results The mixing non-uniformity parameters obtained with the numerically calculated data are generally higher compared to the measured values which is due to the difference in the higher temperature gradients. This also indicates that the numerically modeled results are less mixed compared to the measured values.

In addition to the area weighted results presented it Figures-25 through 28 , the mass flow weighted parameters are also shown. The results indicate that the general trend are also comparable between the area and mass flon weighted parameters; however, significant deviations occur at locations $x / R<0.8$ which is in the domain of jet injection. These results are expected to be different since the are; weighted results do not account for the increment in mass injection through the jet. Since the mass flow weighted results contain the axial velocity term, they reflect this difference. Note that the mass flow weighted deviations for the measured data are not reported herein since the velocity field was not measured by Hatch et al (1992).

The best mixing configuration based on the numerically calculated results shown herein at $x / R=1$ is the $67.5^{\circ}$ slanted slot with $L / W=4$ at $J=52$ (Figures-20, and $28 \mathrm{j}, 28 \mathrm{k}$, and $28 \mathrm{l}$ ), Similarly the best measured configuration with regard to 
mixing uniformity at $x / R=1$ is the slanted slot configuration with a $\mathrm{L} / \mathrm{W}=4$ slant angle range of $\phi=45^{\circ}$ at $\mathrm{J}=52$ (Figures-9. $28 \mathrm{~g}, 28 \mathrm{~h}$, and $28 \mathrm{i}$ ). Both numerically modeled and measured methods therefore show a good comparison as to the mixing uniformity at $x / R=1$. Note that the measured and numerically calculated overall performances were determined based on a numerical average of the AMIX. AHOT, and ACOLD parameters for each specific configuration.

\section{Conclusions}

1) The area weighted parameters compare favorably with the mass flow weighted parameters in almost all numerically analyzed configurations at $x / R=1$. It is however noted that due to the definitions of these statistical parameters, differences will be encountered in the region where the jet flow is injected (typically ()$\leq x / R \leq 0.8$ for the cases analyzed herein).

2) The difference between the numerically calculated and measured results increases with increasing circumferential counter-swirl (generally produced by slot slant angles near $45^{\circ}$ and high J) since the mixing development and temperature uniformity improves in the measured results beyond $\mathrm{x} / \mathrm{R}=0.5$. The change in the numerically calculated temperature gradients and mixing uniformity with increasing $x / R$ appears to be small beyond $x / R=0.5$.

3) The radial temperature stratification produced by the slanted slot configurations in the numerically calculated results is significant and therefore large variations in the mixing non-uniformity between these results and the measurements were encountered. In the numerically calculated results, optimum penetration was therefore obtained with relatively shallow jets which became entrained behind the orifice and mix with the entrained hot flow.

4) The numerically calculated results indicate a much larger variation in mixing non-uniformity with a change in slot slant angle as compared to the measured results. For $\mathrm{J}=25$, the jet penetration is shallow enough to mix cold jet flow with hot mainstream gas behind the jet near the outer wall therefore producing increased mixing and lower temperature stratification. As $J$ is further increased, the jet penetrates beyond the recirculation stagnation therefore trapping the colder jet flow towards the inner section of the mixer and producing high temperature stratification towards the outer wall of the mixer.

5) The increase in J. creating an over-penetrating jet situation, slightly improves the mixing uniformity due to additional mixing produced upstrean of the orifice due to the jet impingement recirculation which allows cold air to be entrained behind the orifice and mix with the hot mainstream flow.
6) The general trends shown in the numerically calculated results are similar to the measured results and the best overall mixing configurations are comparable; however, the comparison between the numerically calculated and measured results must be made at the same locations to equally bias both results for an accurate comparison.

\section{Acknowledgements}

This work was supported by NASA Contract NAS3-25950. Task Order \# 1

\section{References}

Bain. D.B.. Smith, C.E.. and Holdeman, J.D.."CFD Mixing Analysis of Jets Injected from Straight and Slanted Slots into Confined Crossflow in Rectangular Ducts." AIAA paper No. 92-3087, July 8, 1992 (NASA TM 105699).

Hatch. M.S., Sowa, W.A.. Samuelsen, G.S., and Holdeman, J.D.. "Jet Mixing Into a Heated Cross Flow in a Cylindrical Duct: Influence of Geometry and Flow Variations." AIAA paper No. 92-(0773. Jan 1992 (NASA TM 105390).

Holdeman, J.D., "Mixing of Multiple Jets with a Confined Subsonic Crossflow," AIAA paper No. 91-2458, June 1991 (NASA TM 104412).

Kroll, J.T., Sowa, W.A.. Samuelsen. G.S., and Holdeman. J.D.,"Optimization of Circular Orifice Jets Mixing into a Heated Crossflow in a Cylindrical Duct," AIAA paper No. 93-0249, Jan 14. 1993.

Launder, B.E., and Spalding, D.B.," The Nunnerical Computation of Turbulent Flows," Comp. Methods Appl. Mech. Eng.. Vol 3. pp 269-289.

Liscinsky, D.S.. True, B.. Vranos, A.. and Holdeman. J.D. "Esperimental Study of Cross-Stream Mixing in a Rectangular Ducts," AIAA paper No. 92-3090, July 8. 1992 (NASA TM 106194).

Liscinsky, D.S.. Vranos. A.. and Lohmann. R.P.,"Experimental Study of Crossflow Mixing in Cylindrical and Rectangular Ducts." NASA CR 187141, March 1993.

Mongia, H.C., and Reynolds, R.S., " Combustor Design Criteria Validation," Vol III, USARTL-TR-78-55C, Feb 1979.

Oechsle, V.L., Mongia, H.C., and Holdeman, J.D. " A Parametric Numerical Study of Mixing in a Cylindrical Duct," AIAA paper No. 92-3088, July 1992. 
Patankar,S.V., " Numerical Heat Transfer and Fluid Flows," Hemisphere, Washington D.C., 1980.

Rizk, N.K., Mongia, H.C., "Ultra-Low NOx Rich Lean Combustion." ASME paper No. 90-GT-87, 1990.

Rizk. N.K.. Mongia. H.C.. "Low NOx Rich-Lean Combustion Concept Application." AIAA paper No. 91-1962, June 1991.

Rizk. N.K., Mongia, H.C., "Three-Dimensional NOx Model for Rich/Lean Combustor," AIAA paper No. 93-0251, Jan 14, 1993.

Shaw, R.J., "Engine Technology Challenges for a 21st Century High Civil Speed Transport." AIAA 10th International Symposium on Air Breathing Engines, September 6, 1991 (NASA TM 104361).

Smith, C.E., Talpallikar, M.V., and Holdeman, J.D.,"A CFD Study of Jet Mixing in Reduced Flow Areas for Lower Combustion Emissions." AIAA paper No. 91-2460. June 1991 (NASA TM 104411).

Talpallikar, M.V., Smith, C.E., Lai, M.C., and Holdeman, J.D., " CFD Analysis of Jet Mixing in Low NOx Flametube Combustors." June 1991 (NASA TM 104466).

Vranos, A., Liscinsky, D.S., True, B., and Holdeman, J.D.," Experimental Study of Cross-Stream Mixing in a Cylindrical Duct," AIAA paper No. 91-2459, June 1991 (NASA TM 105180 ). 


\begin{tabular}{|c|c|c|c|c|c|c|c|c|c|c|}
\hline CASE & & 1 & 2 & 3 & 4 & 5 & 6 & 7 & 8 & 9 \\
\hline \multicolumn{11}{|l|}{ OVERALL } \\
\hline $\mathrm{J}(\mathrm{jet} / \mathrm{main})$ & & 26.7 & 55.4 & 84.2 & 26.0 & 28.0 & 30.5 & 51.1 & 53.2 & 57.7 \\
\hline MR (jet/main) & & 2.20 & 2.20 & 2.20 & 2.20 & 2.200 & 2.20 & 2.20 & 2.20 & 2.20 \\
\hline DR (jet/main) & & 1.258 & 1.261 & 1.254 & 1.260 & 1.250 & 1.258 & 1.262 & 1.258 & 1.258 \\
\hline VR (jet/main) & & 4.606 & 6.628 & 8.195 & 4.546 & 4.719 & 4.923 & 6.363 & 6.502 & 6.772 \\
\hline $\mathrm{AR}$ (jet/main) & & 0.379 & 0.263 & 0.214 & 0.384 & 0.372 & 0.355 & 0.274 & 0.269 & 0.258 \\
\hline $\mathrm{DP} / \mathrm{P}$ & $\%$ & 1.38 & 2.86 & 4.34 & 1.35 & 1.44 & 1.57 & 2.64 & 2.74 & 2.97 \\
\hline \multicolumn{11}{|l|}{ MAINSTREAM } \\
\hline$P$ main & Atm. & 1.0 & 1.0 & 1.0 & 1.0 & 1.0 & 1.0 & 1.0 & 1.0 & 1.0 \\
\hline$T_{\text {main }}$ & $\mathbf{K}$ & 373 & 373 & 373 & 376 & 372 & 373 & 374 & 373 & 373 \\
\hline $\mathrm{U}$ main & $\mathrm{m} / \mathrm{sec}$ & 10.5 & 10.5 & 10.5 & 10.6 & 10.5 & 10.5 & 10.5 & 10.5 & 10.5 \\
\hline$\dot{\mathrm{m}}$ main & $\mathrm{kg} / \mathrm{sec}$ & 0.045 & 0.045 & 0.045 & 0.045 & 0.045 & 0.045 & 0.045 & 0.045 & 0.045 \\
\hline Mixer Diameter & m & 0.076 & 0.076 & 0.076 & 0.076 & 0.076 & 0.076 & 0.076 & 0.076 & 0.076 \\
\hline JET & & ROUND & ROUND & ROUND & SLOT & SLOT & SLOT & SLOT & SLOT & SLOT \\
\hline $\mathrm{T}$ jet & $\mathbf{K}$ & 297 & 296 & 298 & 299 & 298 & 297 & 297 & 297 & 297 \\
\hline$V_{\text {jet }}$ & $\mathrm{m} / \mathrm{sec}$ & 48.4 & 69.7 & 86.2 & 48.1 & 49.6 & 51.8 & 67.1 & 68.4 & 71.2 \\
\hline$\dot{\mathrm{m}} \mathrm{jet}$ & $\mathrm{kg} / \mathrm{sec}$ & 0.100 & 0.100 & 0.100 & \begin{tabular}{|l|}
0.100 \\
\end{tabular} & 0.100 & 0.100 & 0.100 & 0.100 & 0.100 \\
\hline Acd jet/row & $m^{2}$ & $1.731 \mathrm{e}-03$ & $1.201 \mathrm{e}-03$ & $9.765 e-04$ & \begin{tabular}{|l|}
$1.753 \mathrm{e}-03$ \\
\end{tabular} & $1.696 \mathrm{e}-03$ & \begin{tabular}{|l}
$1.620 \mathrm{e}-03$ \\
\end{tabular} & $1.249 \mathrm{e}-03$ & $1.226 \mathrm{e}-03$ & $1.177 \mathrm{e}-03$ \\
\hline Orifice Cd & & 0.75 & 0.76 & 0.74 & 0.79 & 0.75 & 0.73 & 0.75 & 0.75 & 0.71 \\
\hline Number of orifices & & 8 & 8 & 8 & 8 & 8 & 8 & 8 & 8 & 8 \\
\hline Orifice aspect ratio (L/W) & & 1 & 1 & 1 & 4 & 4 & 4 & 4 & 4 & 4 \\
\hline Slant angle & degrees & 0 & 0 & 0 & 0.0 & 22.5 & 45 & 0 & 22.5 & 45.0 \\
\hline Orifice length & m & 0.017 & 0.014 & 0.012 & 0.030 & 0.030 & 0.029 & 0.026 & 0.025 & 0.025 \\
\hline Orifice width & $\mathbf{m}$ & 0.017 & 0.014 & 0.012 & 0.008 & 0.007 & 0.007 & 0.006 & 0.006 & 0.006 \\
\hline Blockage & & 0.555 & 0.462 & 0.417 & 0.254 & 0.537 & 0.763 & 0.215 & 0.457 & 0.650 \\
\hline Orifice T.E. $x / R$ & & 0.436 & 0.363 & 0.327 & 0.799 & 0.741 & 0.599 & 0.674 & 0.630 & 0.511 \\
\hline
\end{tabular}

\begin{tabular}{|c|c|c|c|c|c|c|c|c|c|c|}
\hline CASE & & 10 & 11 & 12 & 13 & 14 & 15 & 16 & 17 & 18 \\
\hline \multicolumn{11}{|l|}{ OVERALL } \\
\hline $\mathrm{J}$ (jet/main) & & 59.9 & 93.3 & 88.1 & 93.0 & 99.3 & 106.3 & 28.1 & 50.9 & 88.5 \\
\hline $\mathrm{MR}$ (jet/main) & & 2.20 & 2.20 & 2.20 & 2.20 & 2.20 & 2.20 & 2.20 & 2.20 & 2.20 \\
\hline DR (jet/main) & & 1.258 & 1.257 & 1.261 & 1.253 & 1.254 & 1.252 & 1.258 & 1.258 & 1.254 \\
\hline VR (jet/main) & & 6.899 & 8.630 & 8.359 & 8.627 & 8.900 & 9.218 & 4.725 & 6.360 & 8.402 \\
\hline AR (jet/main) & & 0.253 & 0.203 & 0.209 & 0.204 & 0.197 & 0.191 & 0.370 & 0.275 & 0.209 \\
\hline $\mathrm{DP} / \mathrm{P}$ & $\%$ & 3.09 & 4.81 & 4.52 & 4.80 & 5.12 & 5.40 & 1.45 & 2.62 & 4.56 \\
\hline \multicolumn{11}{|l|}{ MAINSTREAM } \\
\hline$P_{\text {main }}$ & Atm. & 1.0 & 1.0 & 1.0 & 1.0 & 1.0 & 1.0 & 1.0 & 1.0 & 1.0 \\
\hline$T$ main & $\mathbf{K}$ & 373 & 374 & 372 & 374 & 373 & 368 & 373 & 373 & 373 \\
\hline $\mathrm{U}$ main & $\mathrm{m} / \mathrm{sec}$ & 10.5 & 10.5 & 10.5 & 10.5 & 10.5 & 10.4 & 10.5 & 10.5 & 10.5 \\
\hline$\dot{\mathrm{m}}$ main & $\mathrm{kg} / \mathrm{sec}$ & 0.045 & 0.045 & 0.045 & 0.045 & 0.045 & 0.045 & 0.045 & 0.045 & 0.045 \\
\hline Mixer Diameter & m & 0.076 & 0.076 & 0.076 & 0.076 & 0.076 & 0.076 & 0.076 & 0.076 & 0.076 \\
\hline JET & & SLOT & SLOT & SLOT & SLOT & SLOT & SLOT & SLOT & SLOT & SLOT \\
\hline$T$ jet & $\mathbf{K}$ & 297 & 298 & 295 & 298 & 298 & 294 & 297 & 297 & 298 \\
\hline $\mathrm{V}$ jet & $\mathrm{m} / \mathrm{sec}$ & 72.6 & 90.8 & 87.5 & 90.7 & 93.6 & 95.6 & 49.7 & 66.9 & 88.4 \\
\hline$\dot{\mathrm{m}}$ jet & $\mathrm{kg} / \mathrm{sec}$ & 0.100 & 0.100 & 0.100 & 0.100 & 0.100 & 0.100 & 0.100 & 0.100 & 0.100 \\
\hline ACd jet/row & $\mathbf{m}^{2}$ & $1.155 \mathrm{e}-03$ & $9.262 \mathrm{e}-04$ & $9.519 \mathrm{e}-04$ & $9.293 \mathrm{e}-04$ & $8.993 \mathrm{e}-04$ & $8.697 \mathrm{e}-04$ & $1.687 \mathrm{e}-03$ & $1.254 \mathrm{e}-03$ & $9.523 \mathrm{e}-04$ \\
\hline Orifice Cd & & 0.70 & 0.74 & 0.76 & 0.73 & 0.71 & 0.68 & 0.75 & 0.77 & 0.76 \\
\hline Number of orifices & & 8 & 8 & 8 & 8 & 8 & 8 & 8 & 8 & 8 \\
\hline Orifice aspect ratio (L/W) & & 4 & 4 & 4 & 4 & 4 & 4 & 8 & 8 & 8 \\
\hline Slant angle & degrees & 67.5 & 0.0 & 22.5 & 45.0 & 67.5 & 90.0 & 45 & 45 & 45 \\
\hline Orifice length & m & 0.025 & 0.022 & 0.022 & 0.022 & 0.022 & 0.021 & 0.042 & 0.036 & 0.031 \\
\hline Orifice width & $\mathbf{m}$ & 0.006 & 0.006 & 0.006 & 0.006 & 0.005 & 0.005 & 0.005 & 0.004 & 0.004 \\
\hline Blockage & & 0.779 & 0.185 & 0.402 & 0.578 & 0.687 & 0.716 & 1.035 & 0.892 & 0.777 \\
\hline Orifice T.E. $\mathrm{x} / \mathrm{R}$ & & 0.348 & 0.581 & 0.555 & 0.454 & 0.307 & 0.141 & 0.813 & 0.701 & 0.611 \\
\hline
\end{tabular}

Table-1. Overall description of the operating conditions and geometric dimensions 


\begin{tabular}{|c|c|c|c|c|c|c|c|c|c|c|c|c|c|}
\hline \multirow{2}{*}{$\begin{array}{c}\text { Config } \\
\# \\
\end{array}$} & \multirow[t]{2}{*}{$\mathrm{L} / \mathrm{W}$} & \multirow{2}{*}{$\frac{\phi}{\text { degrees }}$} & \multirow{2}{*}{$\begin{array}{l}\text { ORIFICE } \\
\text { SHAPE }\end{array}$} & \multirow[t]{2}{*}{$\mathrm{J}$} & \multicolumn{3}{|c|}{ Numerical calculated results } & \multicolumn{3}{|c|}{ Experimental results } & \multicolumn{3}{|c|}{ Numerical calculated results } \\
\hline & & & & & AMIX & AHOT & ACOLD & AMIX & AHOT & ACOLD & MMIX & MHOT & MCOLD \\
\hline 1 & & & ROUND & 25 & 0.154 & 0.119 & 0.097 & 0.074 & 0.012 & 0.073 & 0.160 & 0.107 & 0.119 \\
\hline 2 & & & ROUND & 52 & 0.183 & 0.149 & 0.106 & 0.093 & 0.063 & 0.069 & 0.195 & 0.128 & 0.148 \\
\hline 3 & & & ROUND & 80 & 0.172 & 0.140 & 0.099 & 0.116 & 0.091 & 0.073 & 0.191 & 0.124 & 0.145 \\
\hline 4 & 4 & 0.0 & SLOT & 25 & 0.176 & 0.117 & 0.132 & - & - & - & 0.189 & 0.115 & 0.150 \\
\hline 5 & 4 & 22.5 & SLOT & 25 & 0.192 & 0.159 & 0.108 & - & - & - & 0.185 & 0.135 & 0.127 \\
\hline 6 & 4 & 45.0 & SLOT & 25 & 0.169 & 0.148 & 0.080 & 0.063 & 0.009 & 0.062 & 0.147 & 0.112 & 0.096 \\
\hline 7 & 4 & 0.0 & SLOT & 52 & 0.147 & 0.101 & 0.106 & 0.080 & 0.044 & 0.067 & 0.166 & 0.104 & 0.129 \\
\hline 8 & 4 & 22.5 & SLOT & 52 & 0.192 & 0.161 & 0.105 & 0.048 & 0.018 & 0.044 & 0.198 & 0.145 & 0.135 \\
\hline 9 & 4 & 45.0 & SLOT & 52 & 0.224 & 0.210 & 0.080 & 0.051 & 0.008 & 0.051 & 0.177 & 0.139 & 0.110 \\
\hline 10 & 4 & 67.5 & SLOT & 52 & 0.093 & 0.076 & 0.054 & 0.050 & 0.012 & 0.049 & 0.088 & 0.044 & 0.076 \\
\hline 11 & 4 & 0.0 & SLOT & 80 & 0.120 & 0.082 & 0.087 & - & - & - & 0.139 & 0.081 & 0.113 \\
\hline 12 & 4 & 22.5 & SLOT & 80 & 0.174 & 0.139 & 0.105 & - & - & - & 0.187 & 0.129 & 0.136 \\
\hline 13 & 4 & 45.0 & SLOT & 80 & 0.216 & 0.199 & 0.084 & 0.086 & 0.075 & 0.042 & 0.182 & 0.134 & 0.124 \\
\hline 14 & 4 & 67.0 & SLOT & 80 & 0.207 & 0.200 & 0.055 & - & - & - & 0.122 & 0.087 & 0.085 \\
\hline 15 & 4 & 90.0 & SLOT & 80 & 0.172 & 0.167 & 0.041 & - & - & - & 0.120 & 0.101 & 0.065 \\
\hline 16 & 8 & 45.0 & SLOT & 25 & 0.148 & 0.117 & 0.091 & 0.101 & 0.048 & 0.089 & 0.156 & 0.114 & 0.106 \\
\hline 17 & 8 & 45.0 & SLOT & 52 & 0.159 & 0.142 & 0.071 & 0.101 & 0.050 & 0.088 & 0.151 & 0.119 & 0.092 \\
\hline 18 & 8 & 45.0 & SLOT & 80 & 0.160 & 0.147 & 0.064 & 0.053 & 0.022 & 0.048 & 0.133 & 0.098 & 0.091 \\
\hline
\end{tabular}

Table-2. Summary of the mixing non-uniformity results for all the analyzed configurations at $x / R=1$ 

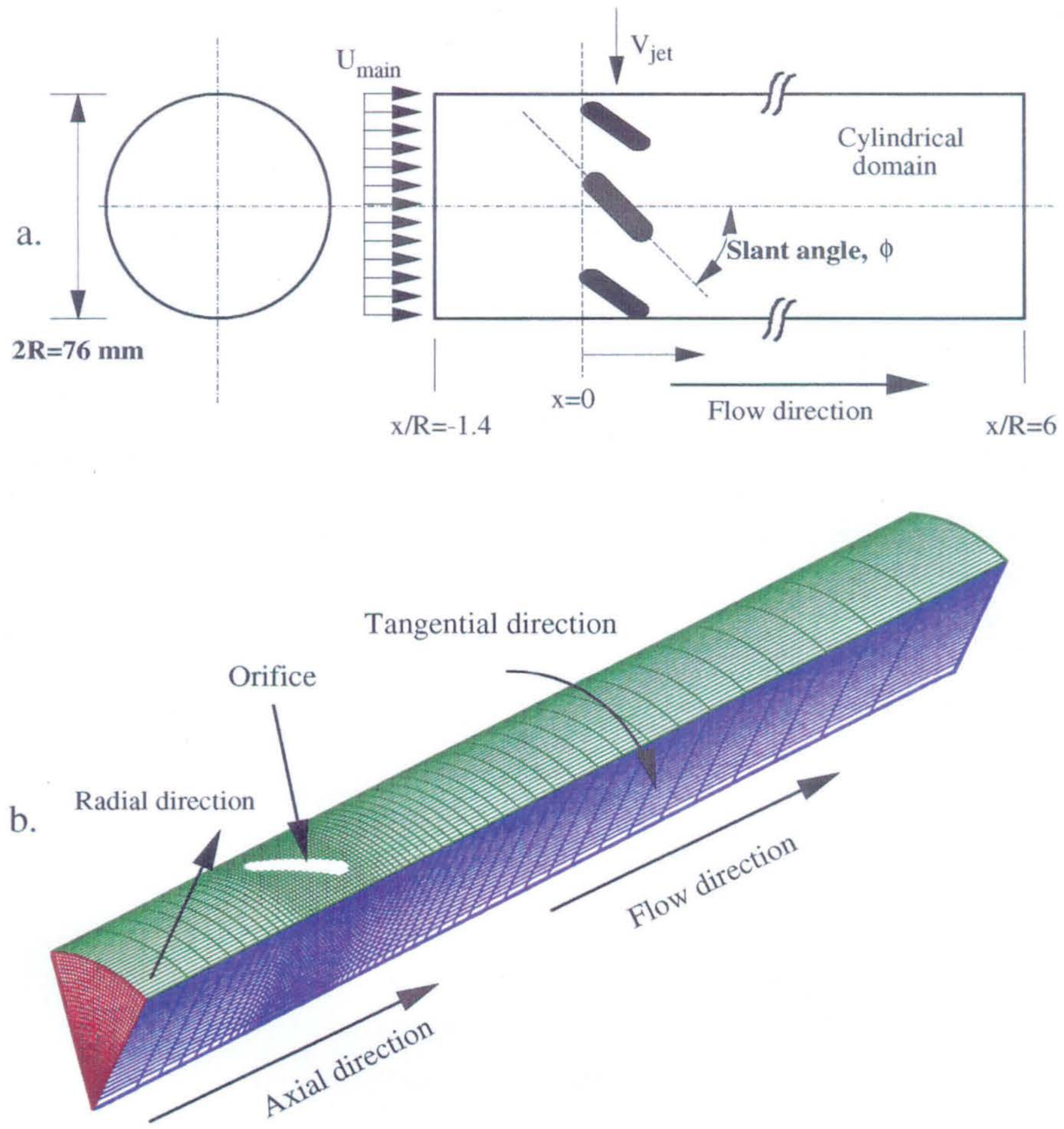

Figure-1 Depiction of (a) geometric configuration of the mixing section; (b) computational grid 


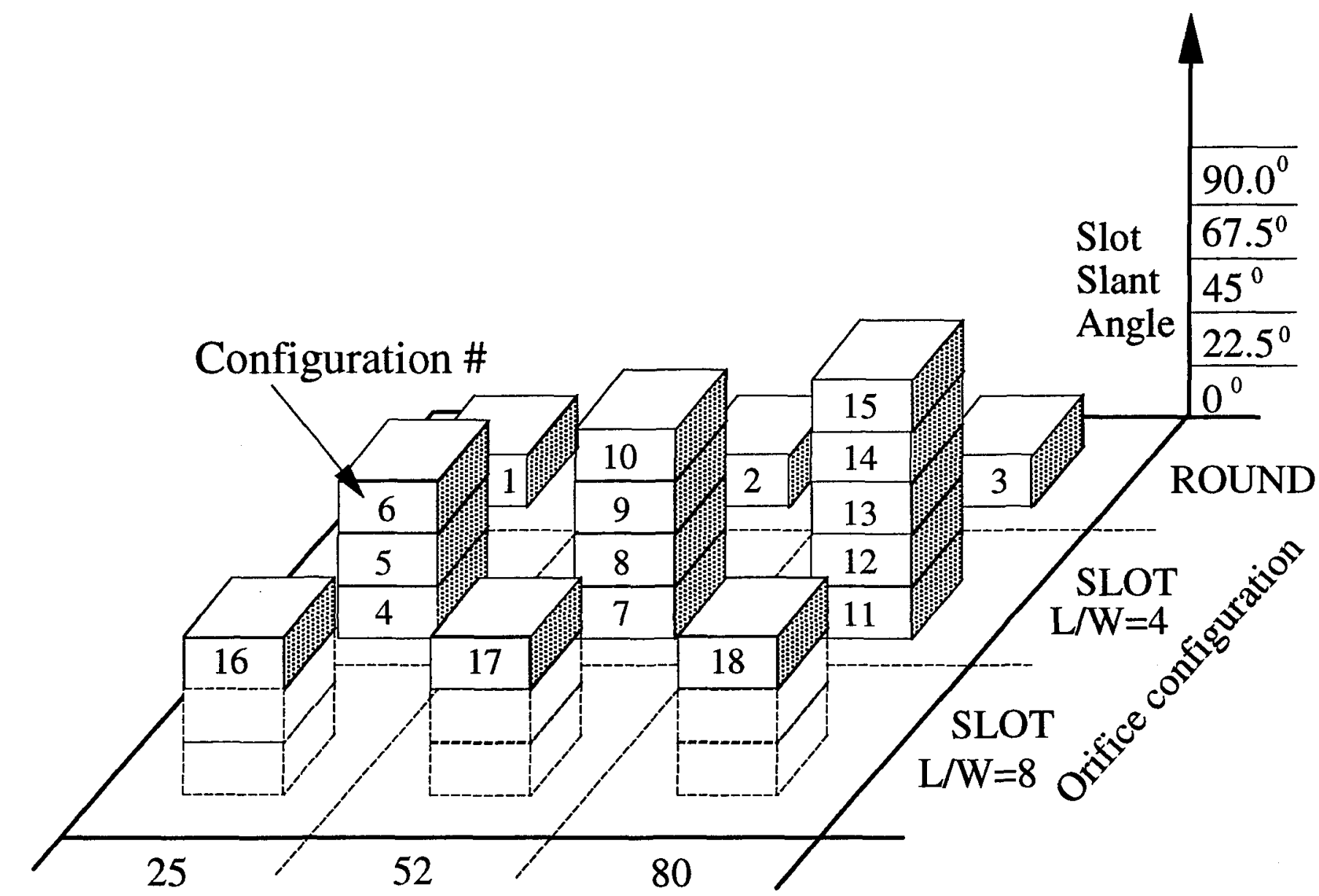

Nominal jet-to-mainstream momentum flux ratio (J)

Figure-2. Matrix of analyzed configurations 

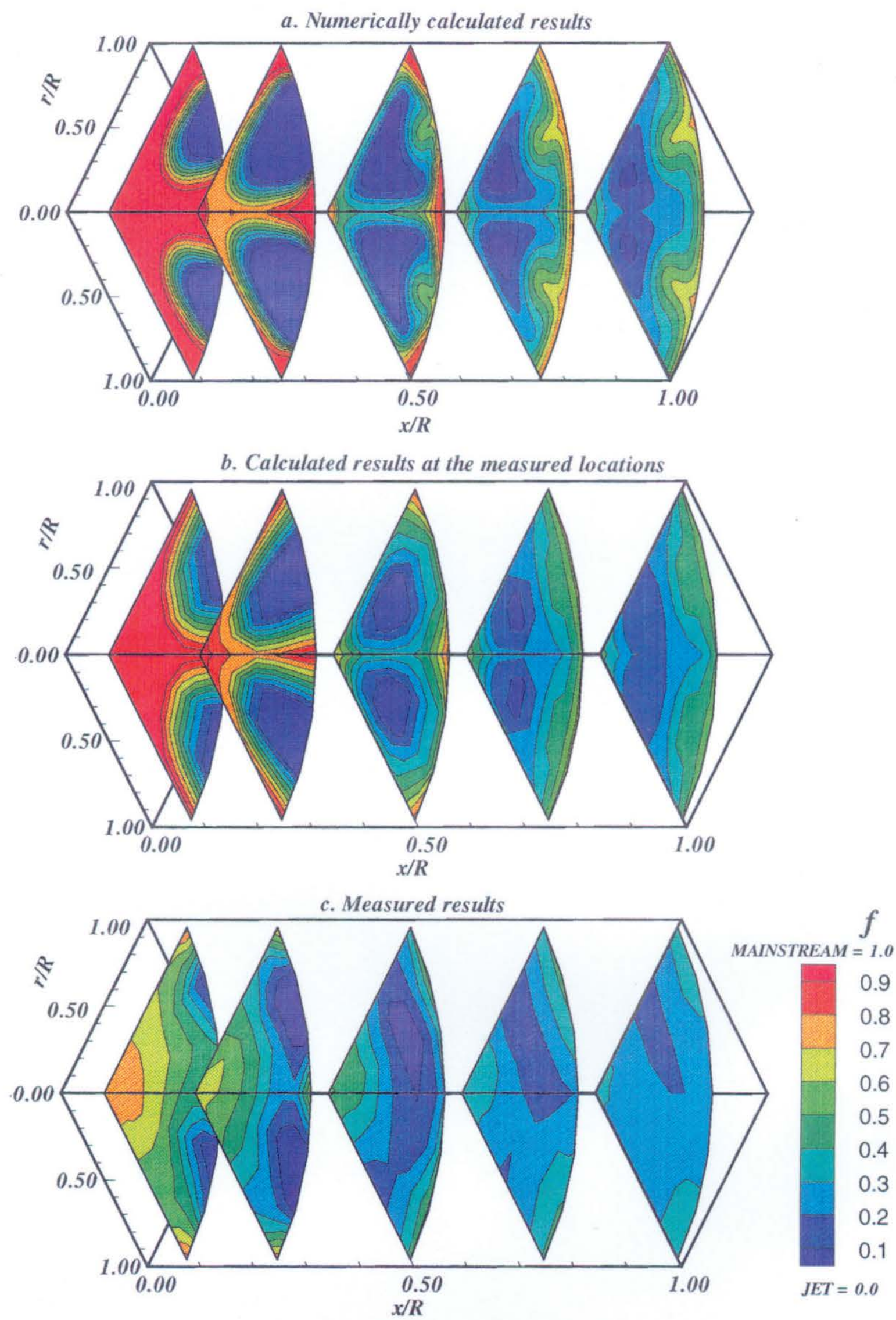

Figure-3. Comparison of the normalized temperature for the numerically calculated and measured results for configuration \# $1, J=26.7, M R=2.2, D R=1.26$, and $T_{e q}=0.313$ Round jet , 8 orifices/row 

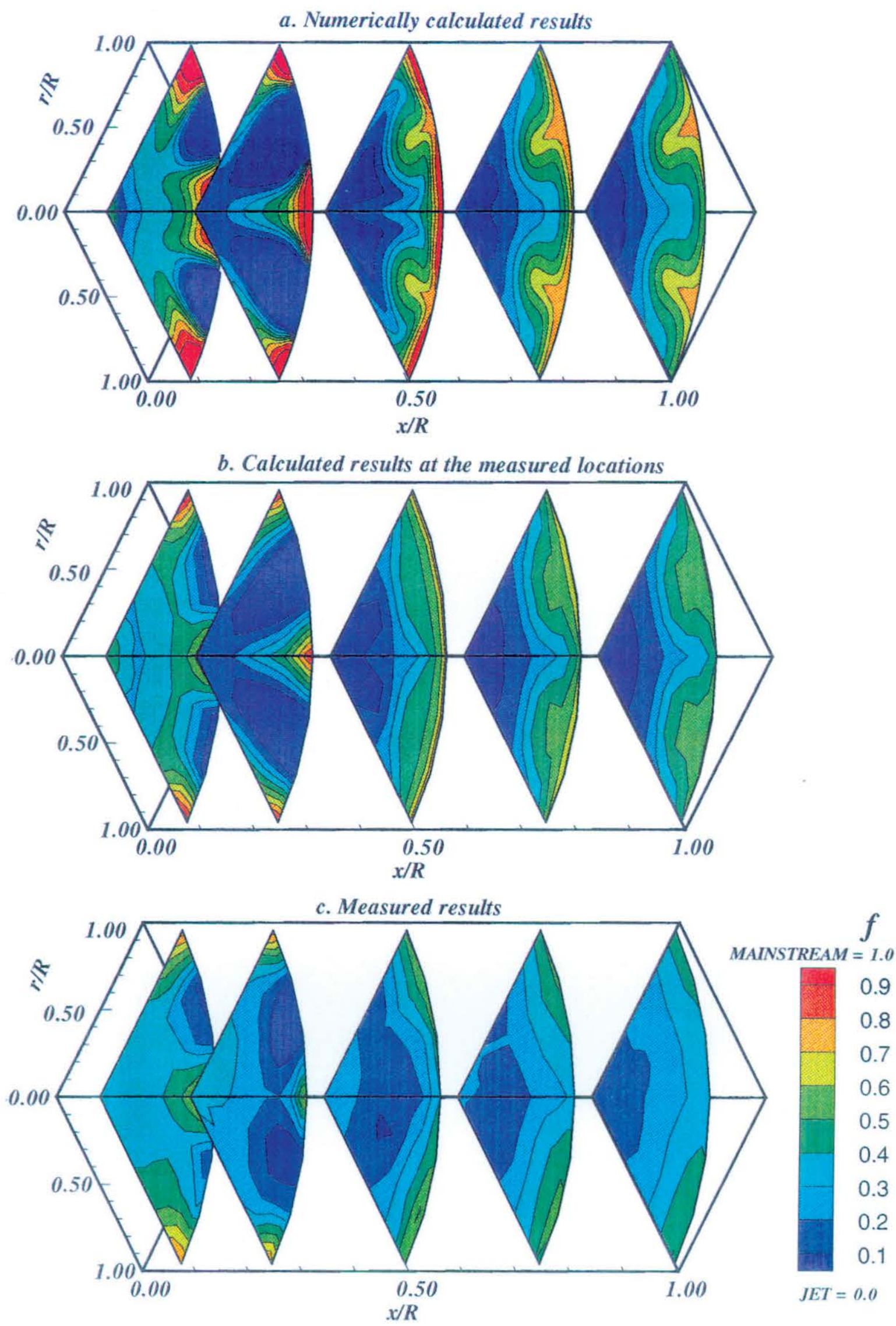

Figure-4. Comparison of the normalized temperature for the numerically calculated and measured results for configuration \# 2, J=55.4, $M R=2.2, D R=1.26$, and $T_{e q}=0.313$ Round jet, 8 orifices/row 

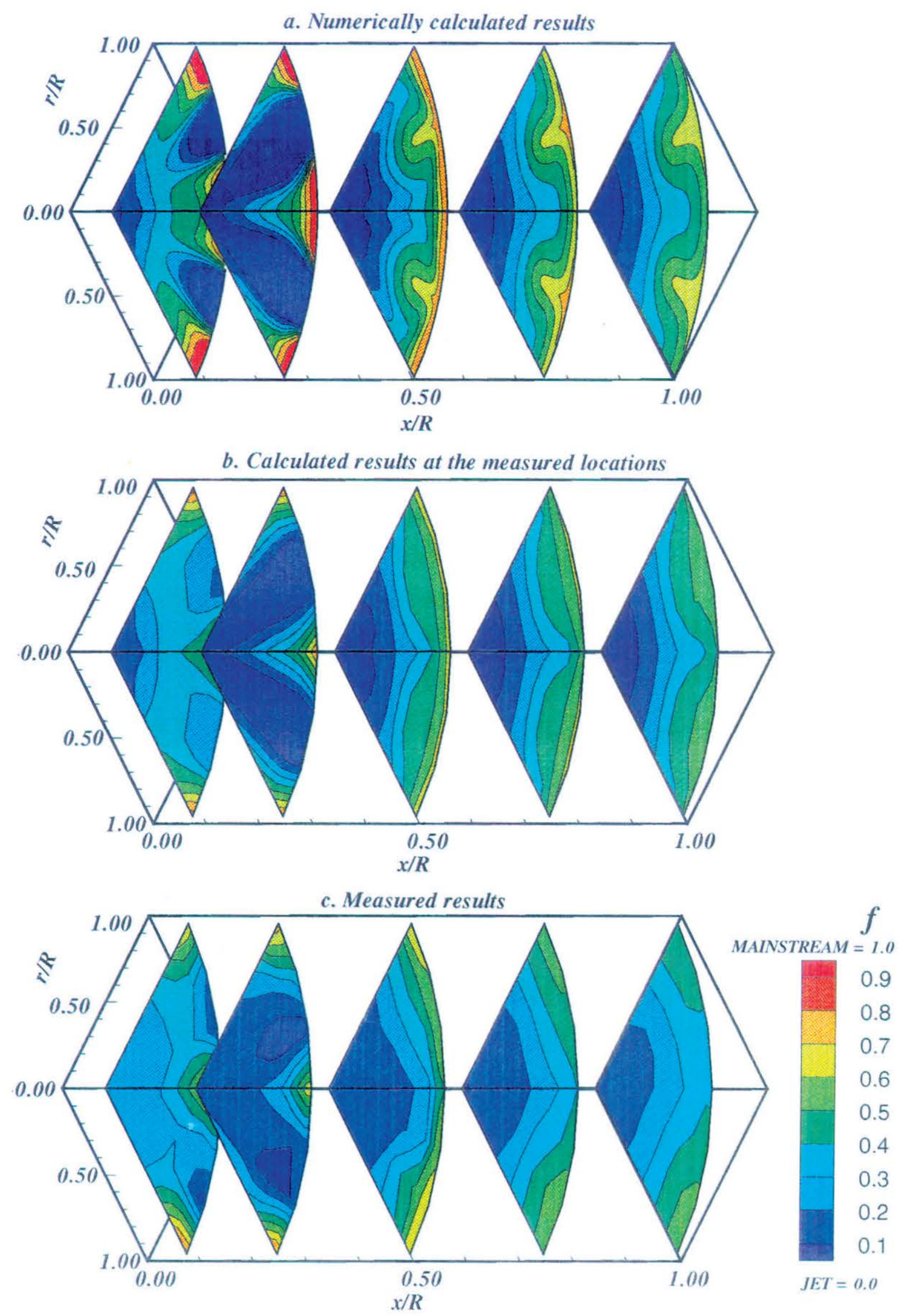

Figure-5. Comparison of the normalized temperature for the numerically calculated and measured results for configuration \# 3, $J=84.2, M R=2.2, D R=1.26$, and $T_{e q}=0.313$ Round jet, 8 orifices/row 

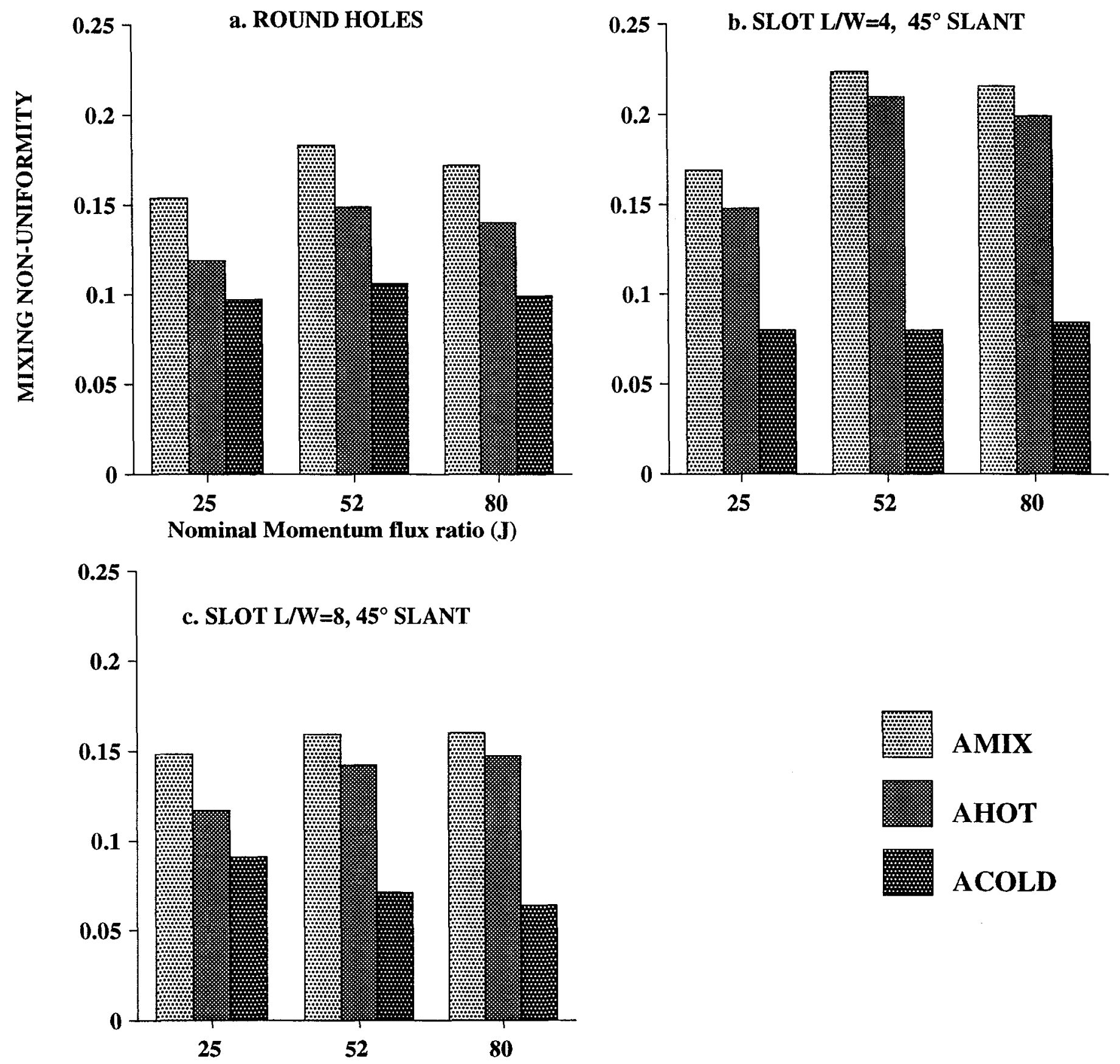

Figure-6. Effect of the increase in $\mathrm{J}$ on the numerically calculated mixing non-uniformity of round holes and slanted slots with aspect ratios of 4 and 8 . 

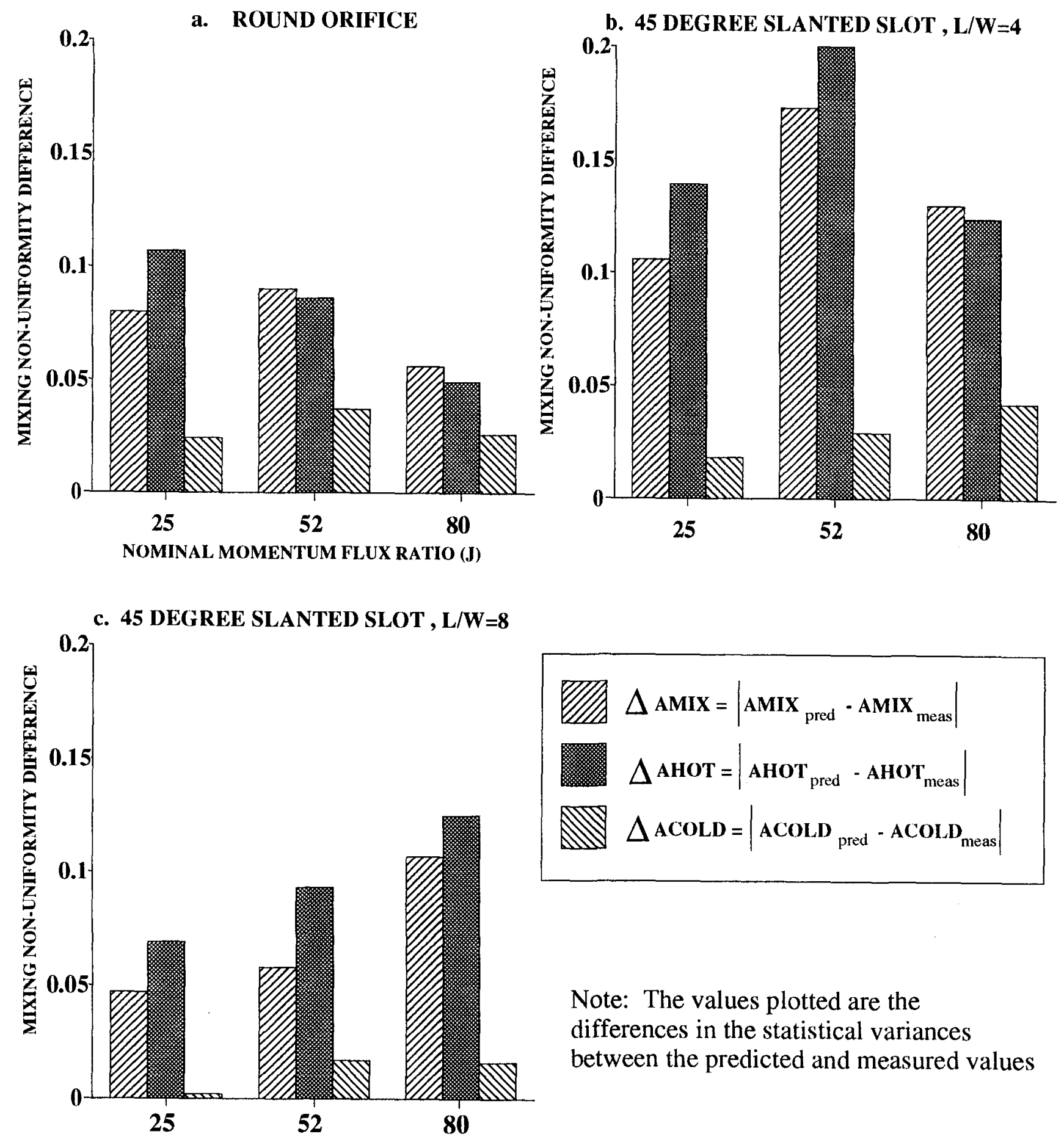

Figure-7. Effect of the increase in J and slant angle on the difference between the numerically calculated and measured results for different orifice configurations. at $\mathrm{x} / \mathrm{R}=1$. 

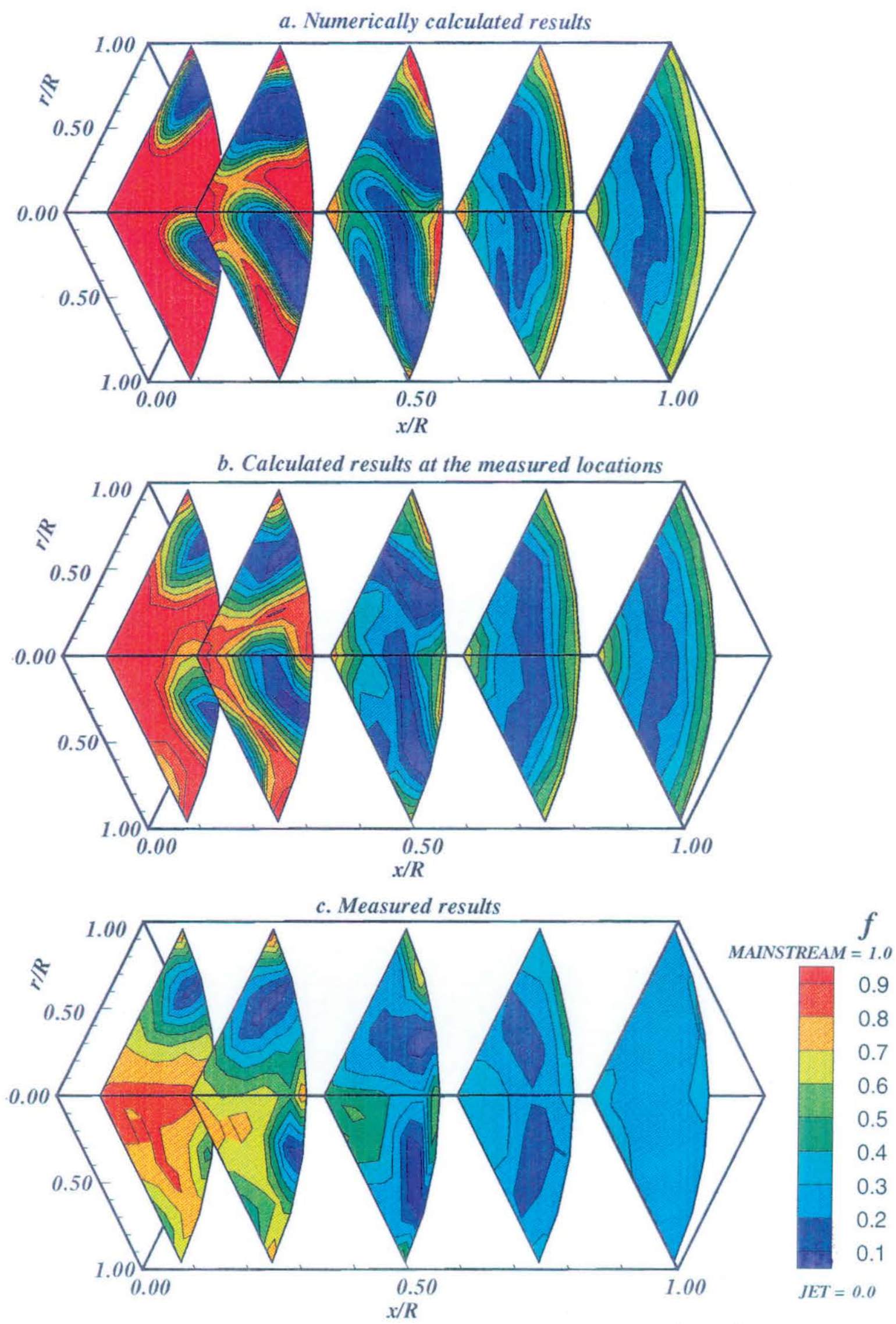

Figure-8. Comparison of the normalized temperature for the numerically calculated and measured results for configuration \# $6, J=30.5, M R=2.2, D R=1.26$, and $T_{e q}=0.313$ $45^{\circ}$ slot, $L / W=4,8$ orifices/row 

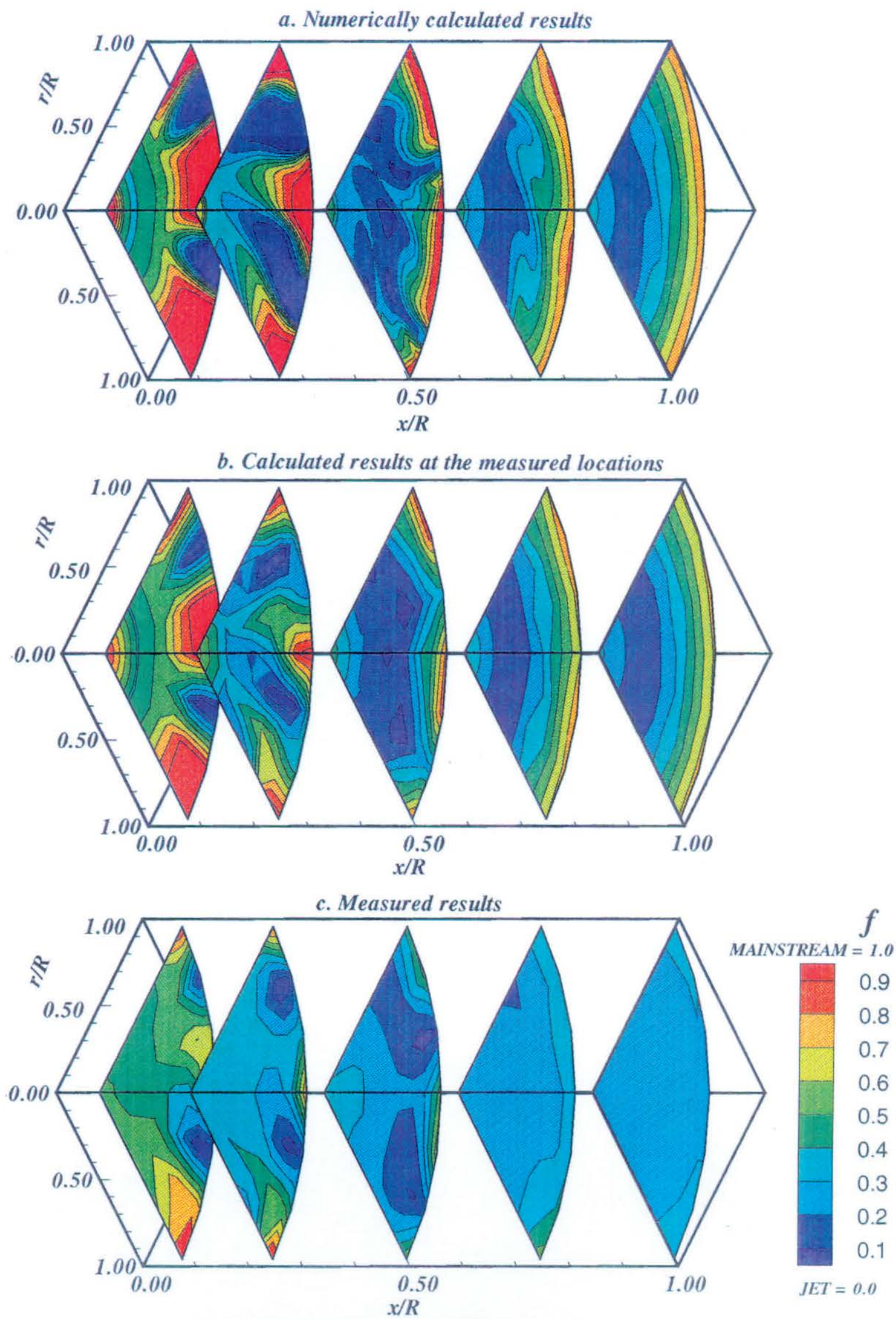

Figure-9. Comparison of the normalized temperature for the numerically calculated and measured results for configuration \# 9, $J=57.7, M R=2.2, D R=1.26$, and $T_{e q}=0.313$ $45^{\circ}$ slot, $L / W=4,8$ orifices/row 

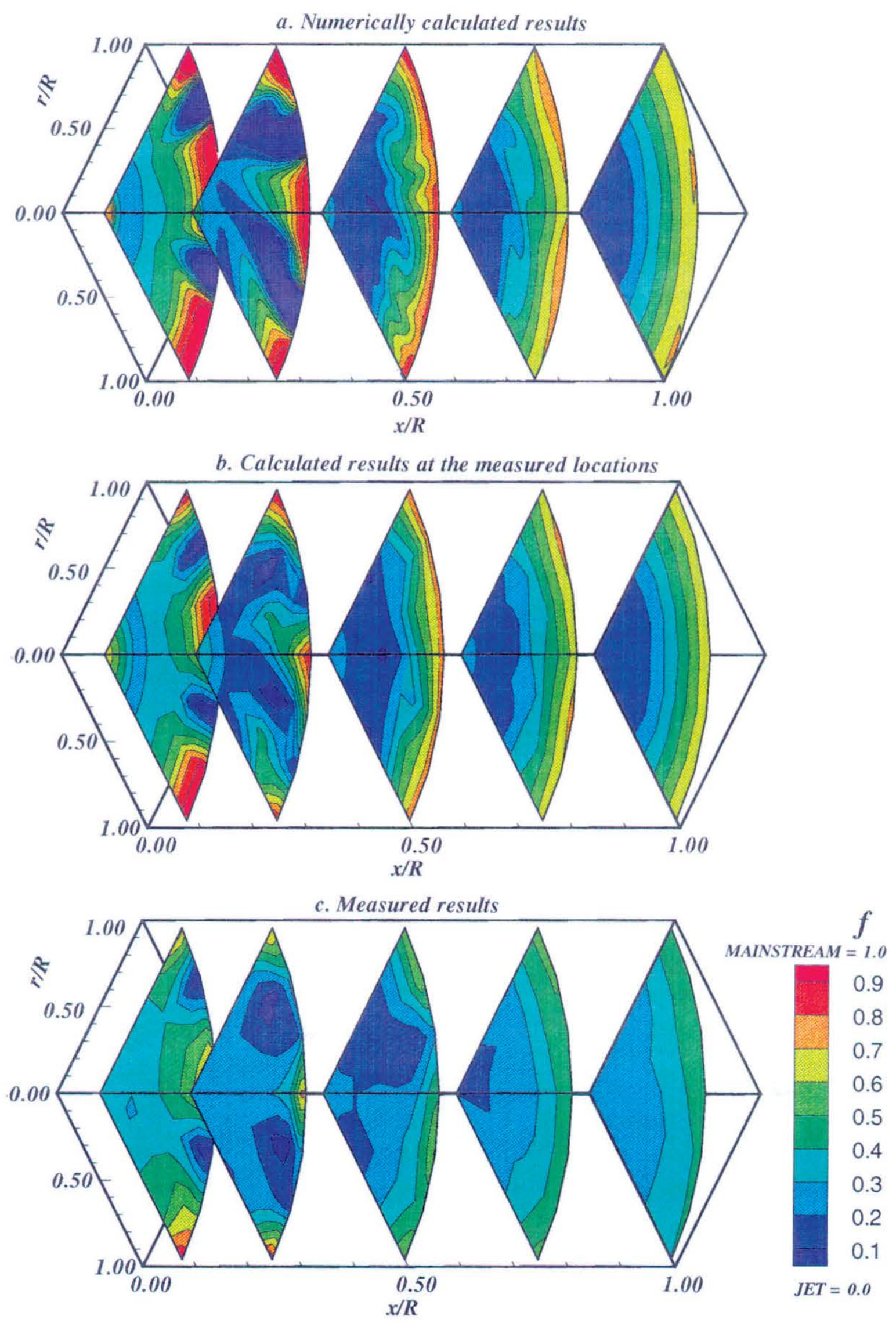

Figure-10. Comparison of the normalized temperature for the numerically calculated and measured results for configuration \# 13, $J=93.0, M R=2.2, D R=1.26$, and $T_{e q}=0.313$ $45^{\circ}$ slot, $L / W=4,8$ orifices/row 
a. Velocity distribution in the radial-tangential plane at $\mathrm{x} / \mathrm{R}=1$ for configuration \# 18, $45 \mathrm{deg}$ slots, $\mathrm{L} / \mathrm{W}=8$

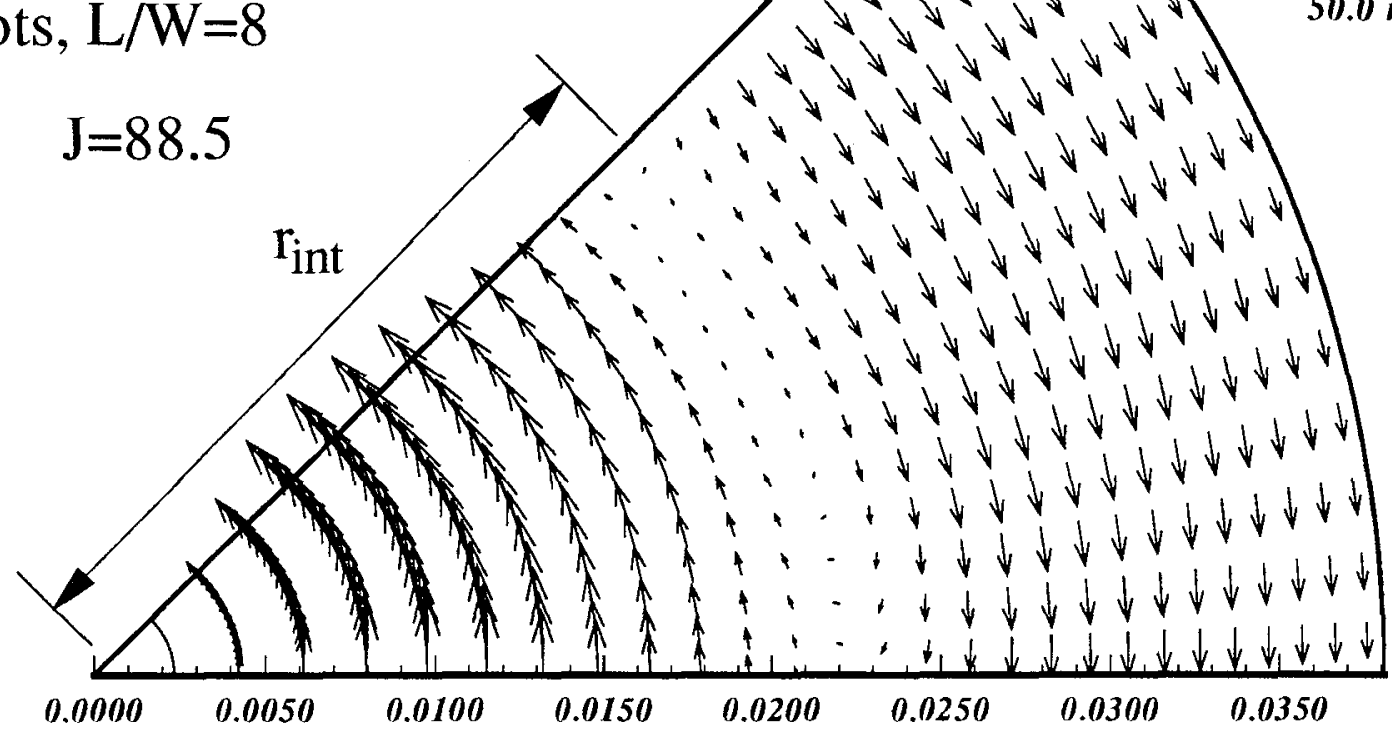

b.

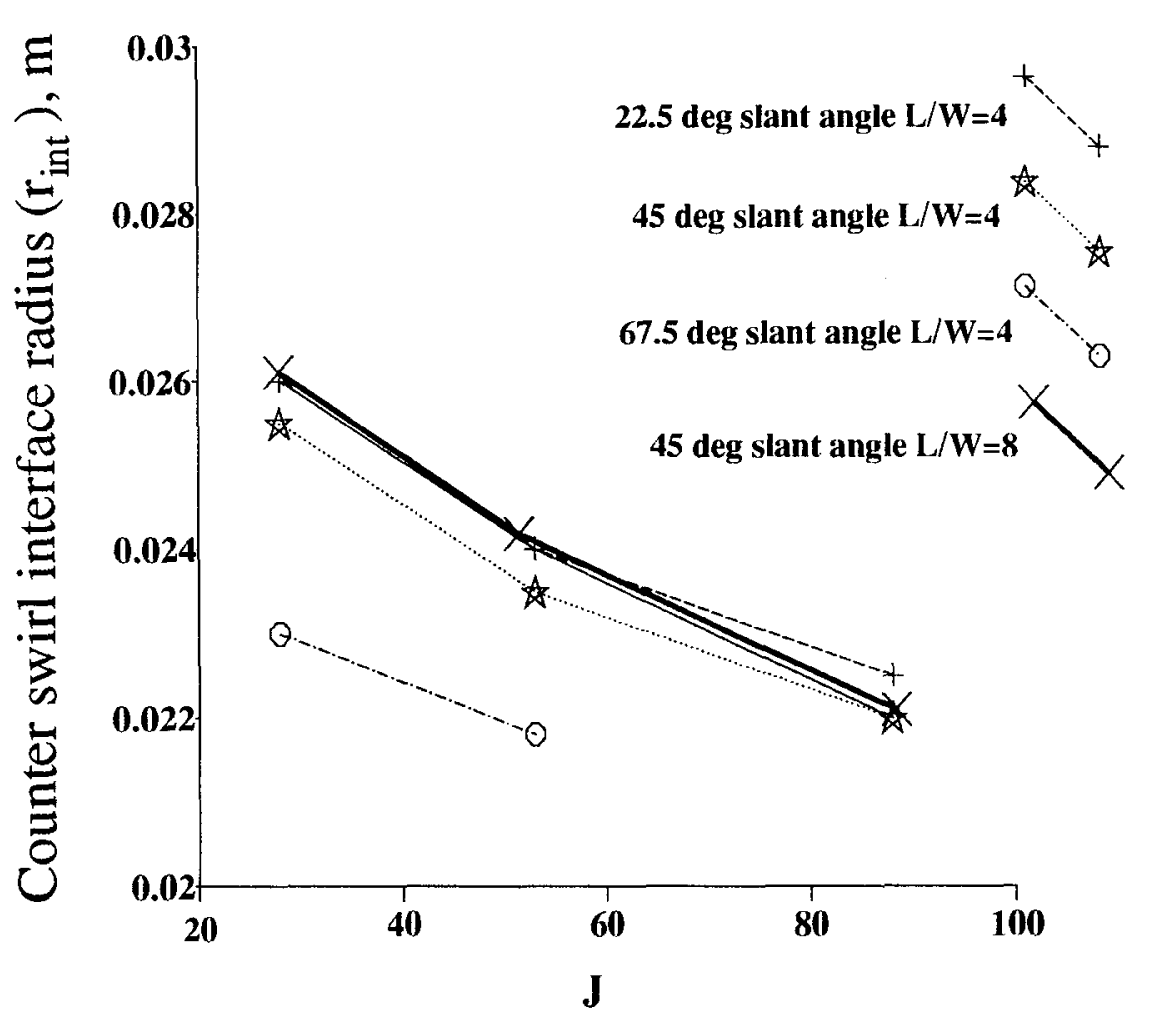

Figure-11 Effect of $\mathrm{J}$ on counter-swirl interface radius for the numerically calculated resutls 

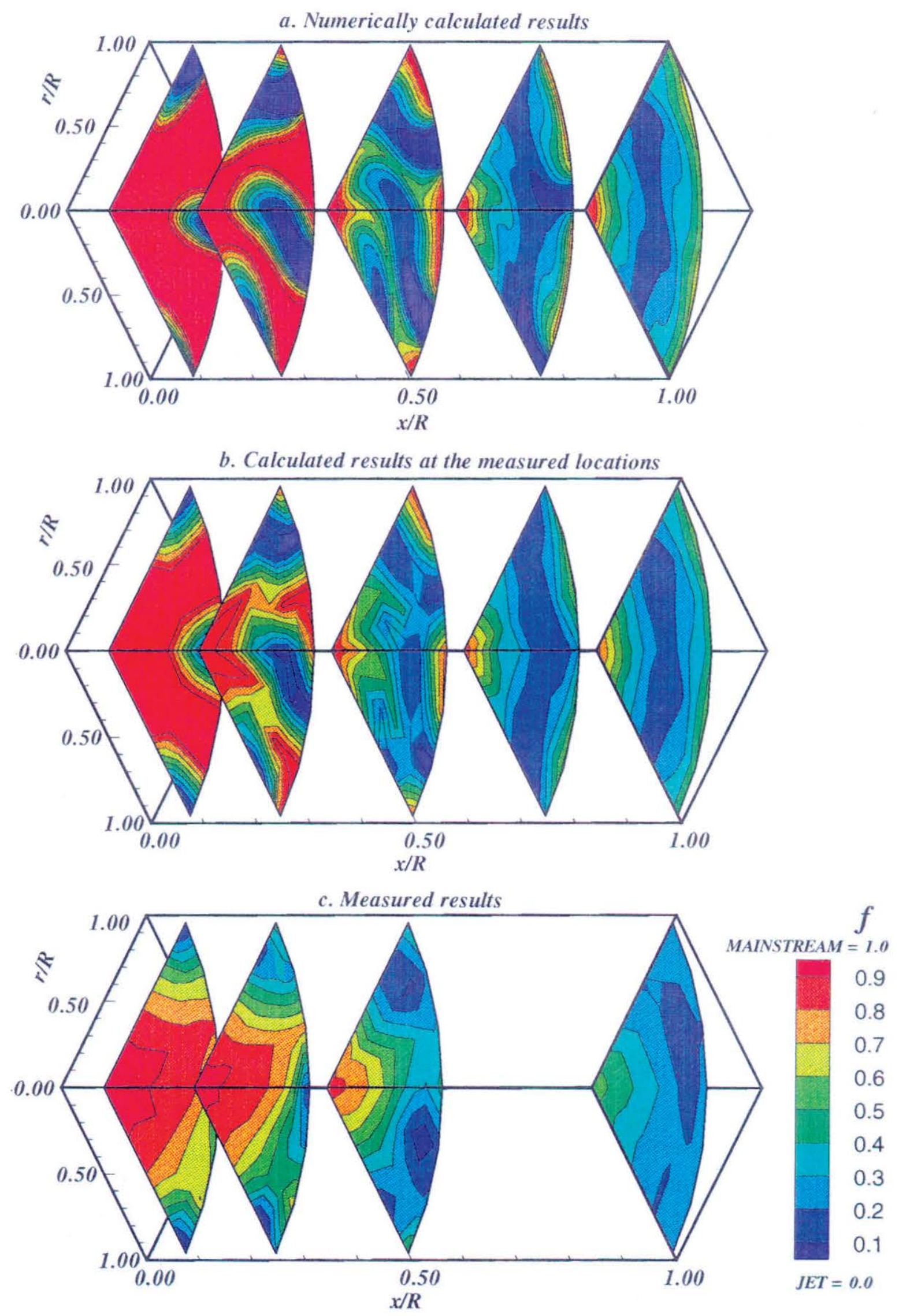

Figure-12. Comparison of the normalized temperature for the numerically calculated and measured results for configuration \# 16, $J=26.7, M R=2.2, D R=1.26$, and $T_{e q}=0.313$ $45^{\circ}$ slot, $L / W=8,8$ orifices/row 

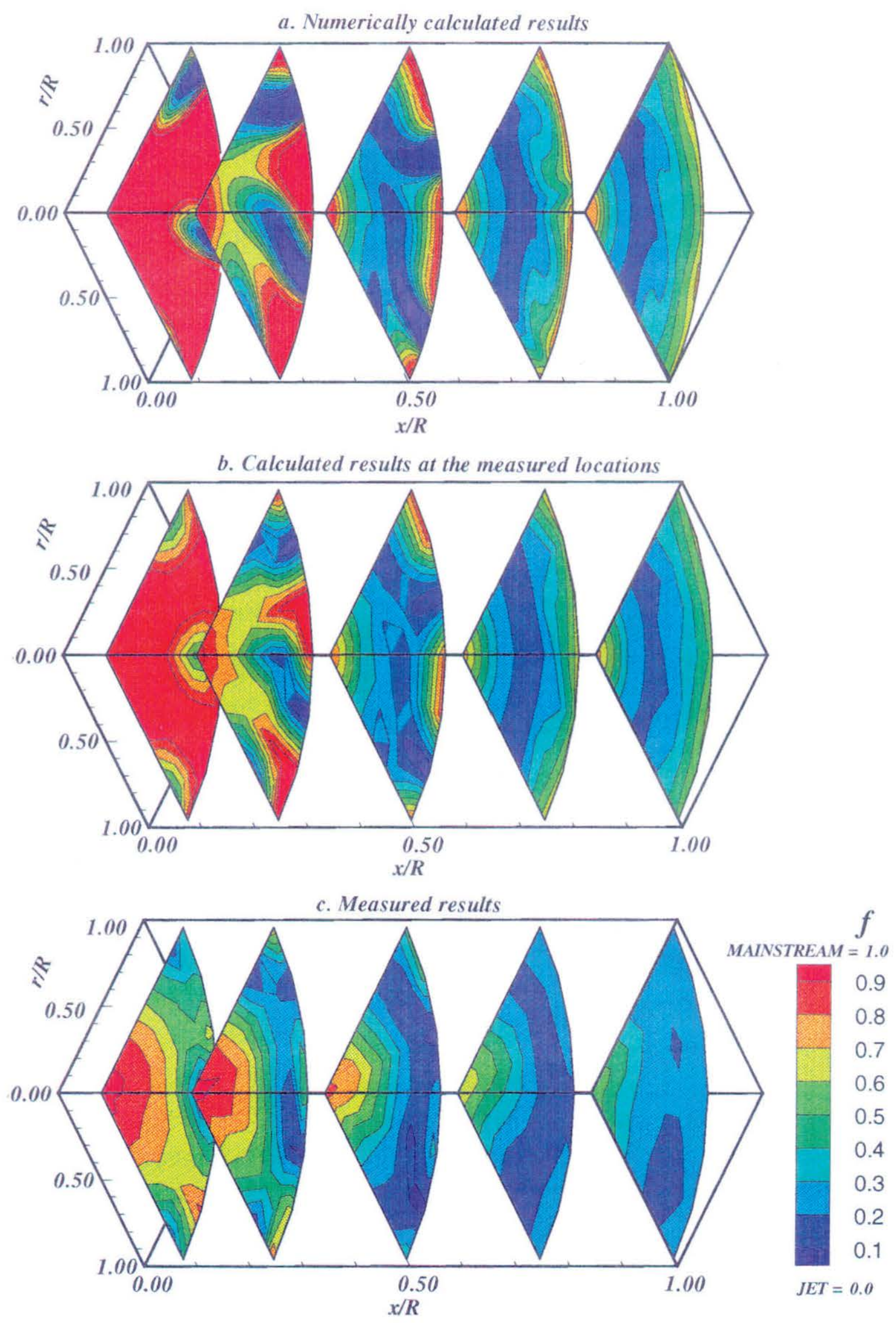

Figure-13. Comparison of the normalized temperature for the numerically calculated and measured results for configuration \# $17, J=50.9, M R=2.2, D R=1.26$, and $T_{e q}=0.313$ $45^{\circ}$ slot, $L / W=8,8$ orifices/row 

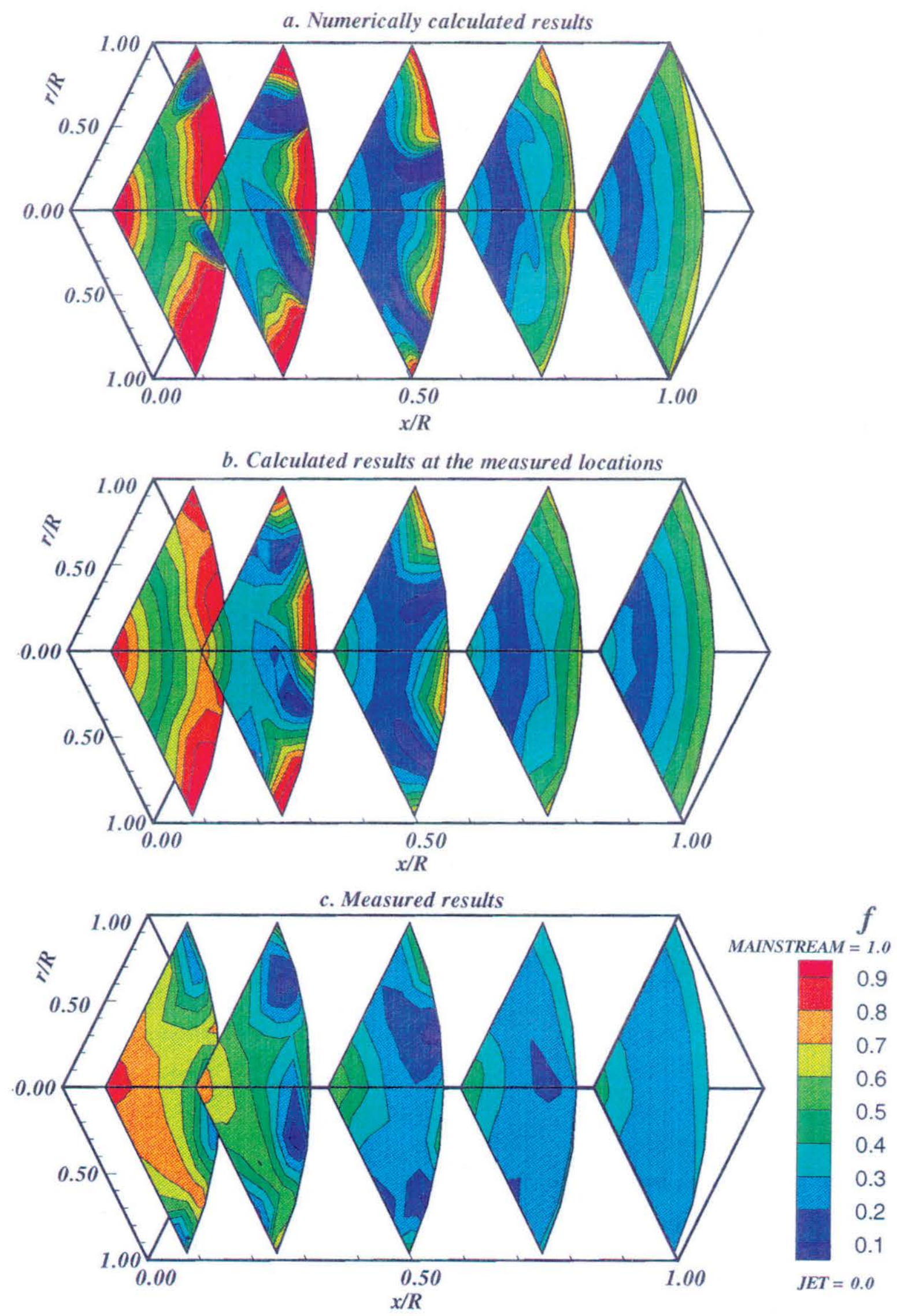

Figure-14. Comparison of the normalized temperature for the numerically calculated and measured results for configuration \# $18, J=88.5, M R=2.2, D R=1.26$, and $T_{e q}=0.313$ $45^{\circ}$ slot, $L / W=8,8$ orifices/row 

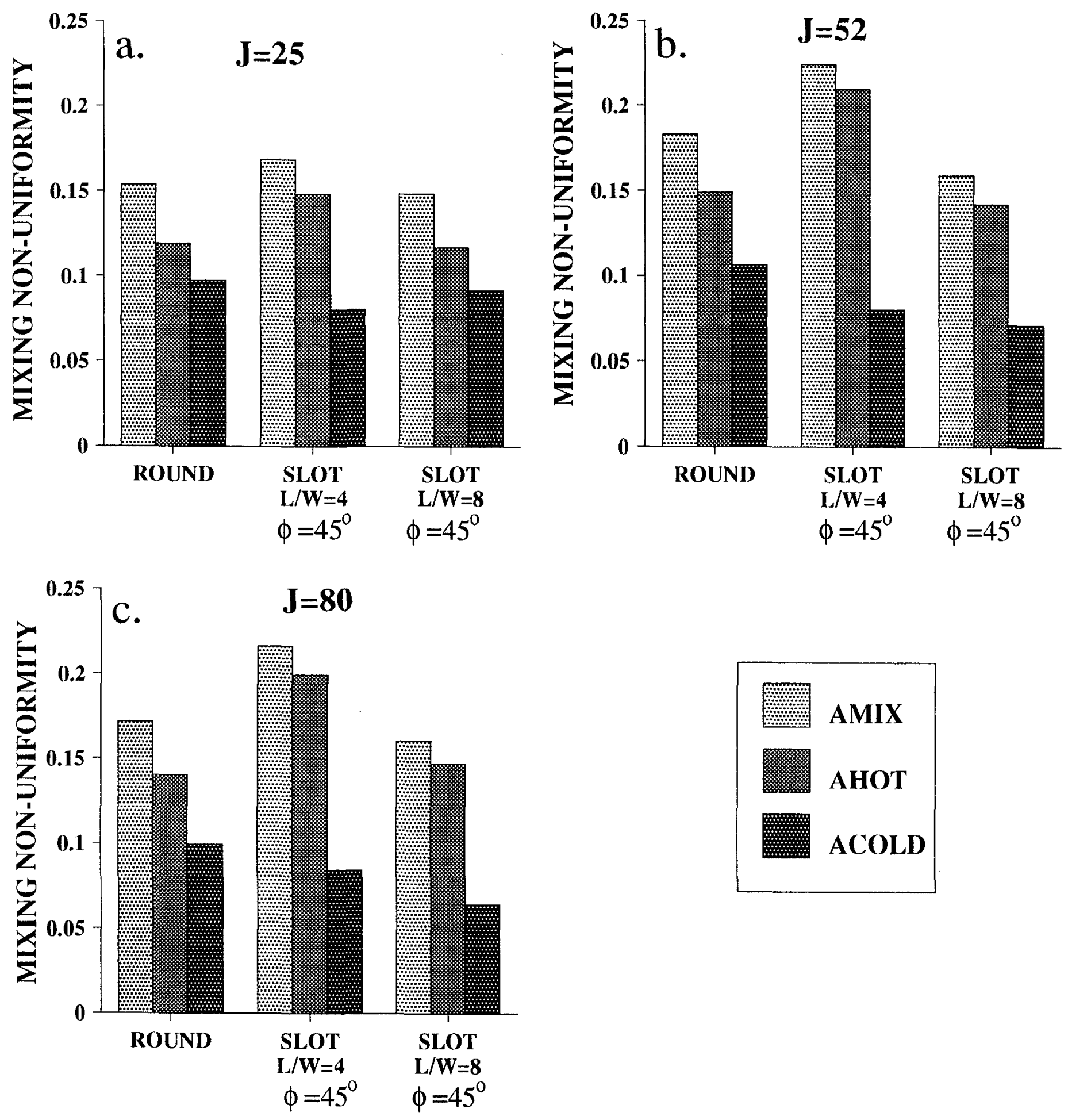

Figure-15. Effect of orifice configuration and slot aspect ratio (L/W) on the numerically calculated mixing non-uniformity for varying $\mathrm{J}$. 

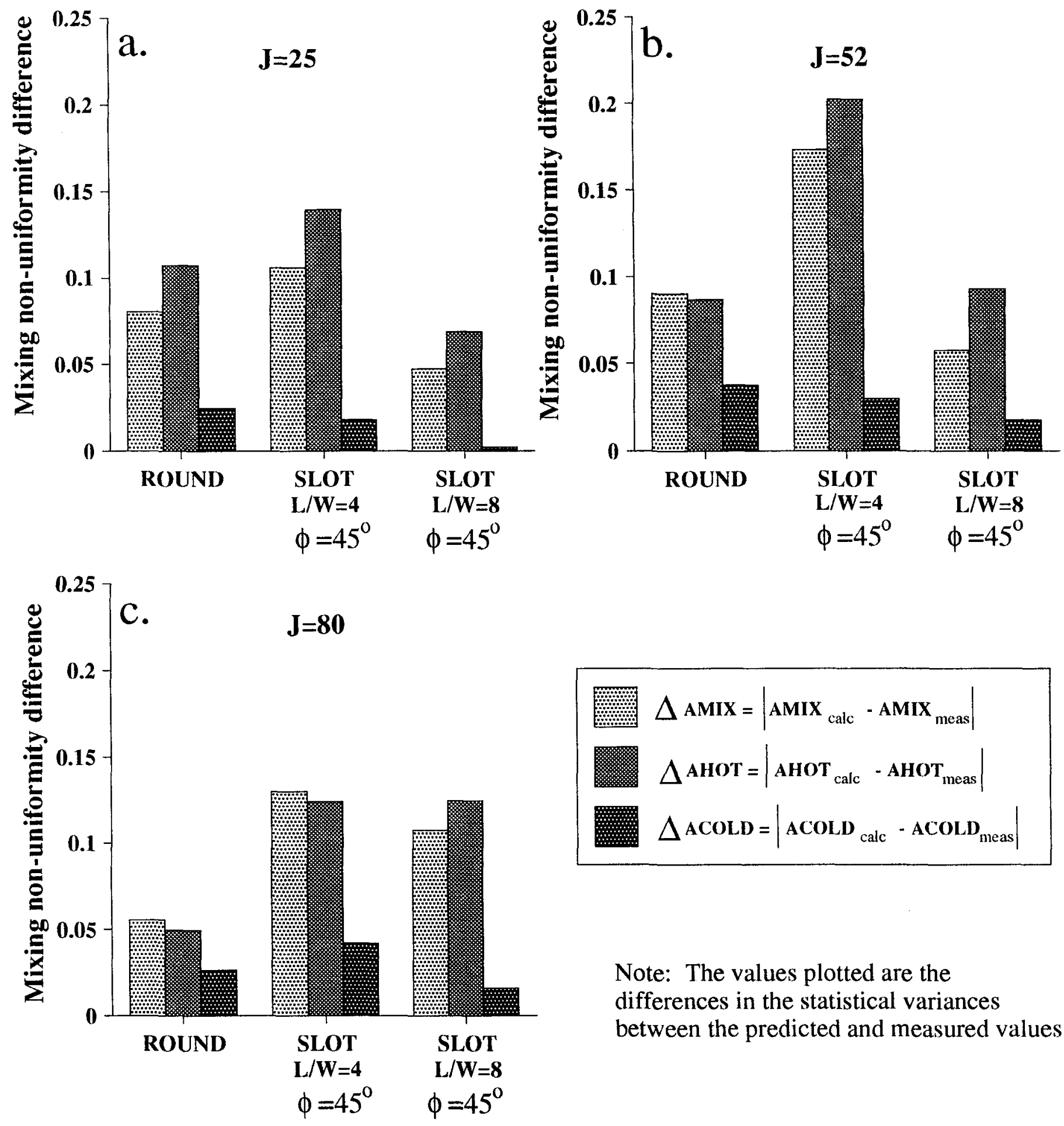

$$
\begin{aligned}
& \triangle \mathrm{AMIX}=\left|\mathrm{AMIX}_{\text {calc }}-\mathrm{AMIX}_{\text {meas }}\right| \\
& \triangle \mathrm{AHOT}=\left|\mathrm{AHOT}_{\text {calc }}-\mathrm{AHOT}_{\text {meas }}\right| \\
& \triangle \mathrm{ACOLD}=\left|\mathrm{ACOLD}_{\mathrm{calc}}-\mathrm{ACOLD}_{\text {meas }}\right|
\end{aligned}
$$

Note: The values plotted are the differences in the statistical variances between the predicted and measured values

Figure-16. Effect of orifice configuration and slant slant angle on the difference between the numerically calculated and measured results at $\mathrm{x} / \mathrm{R}=1$. 

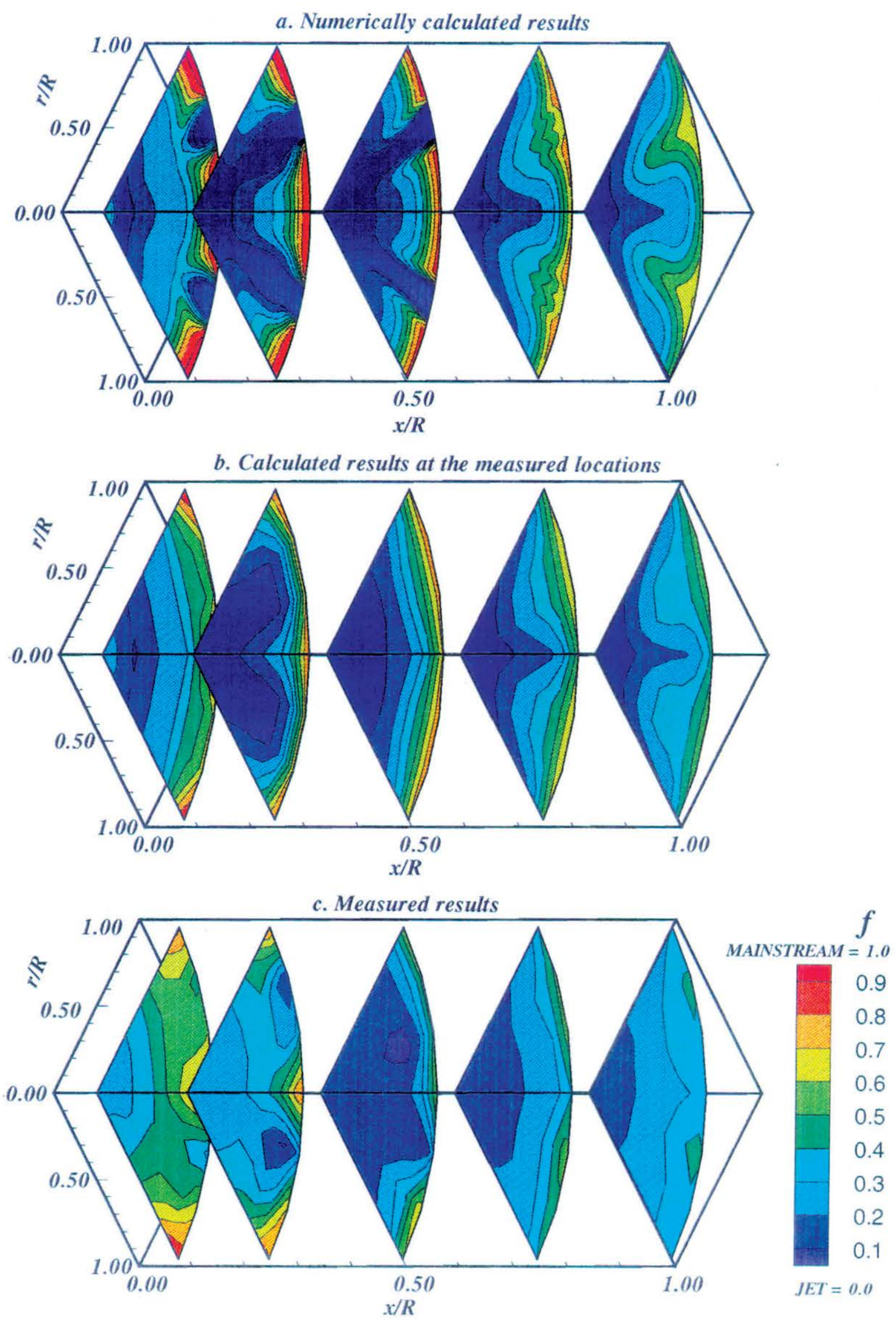

Figure-17. Comparison of the normalized temperature for the numerically calculated and measured results for configuration \# 7, $J=51.1, M R=2.2, D R=1.26$, and $T_{e q}=0.313$ Aligned slot, $L / W=4,8$ orifices/row 

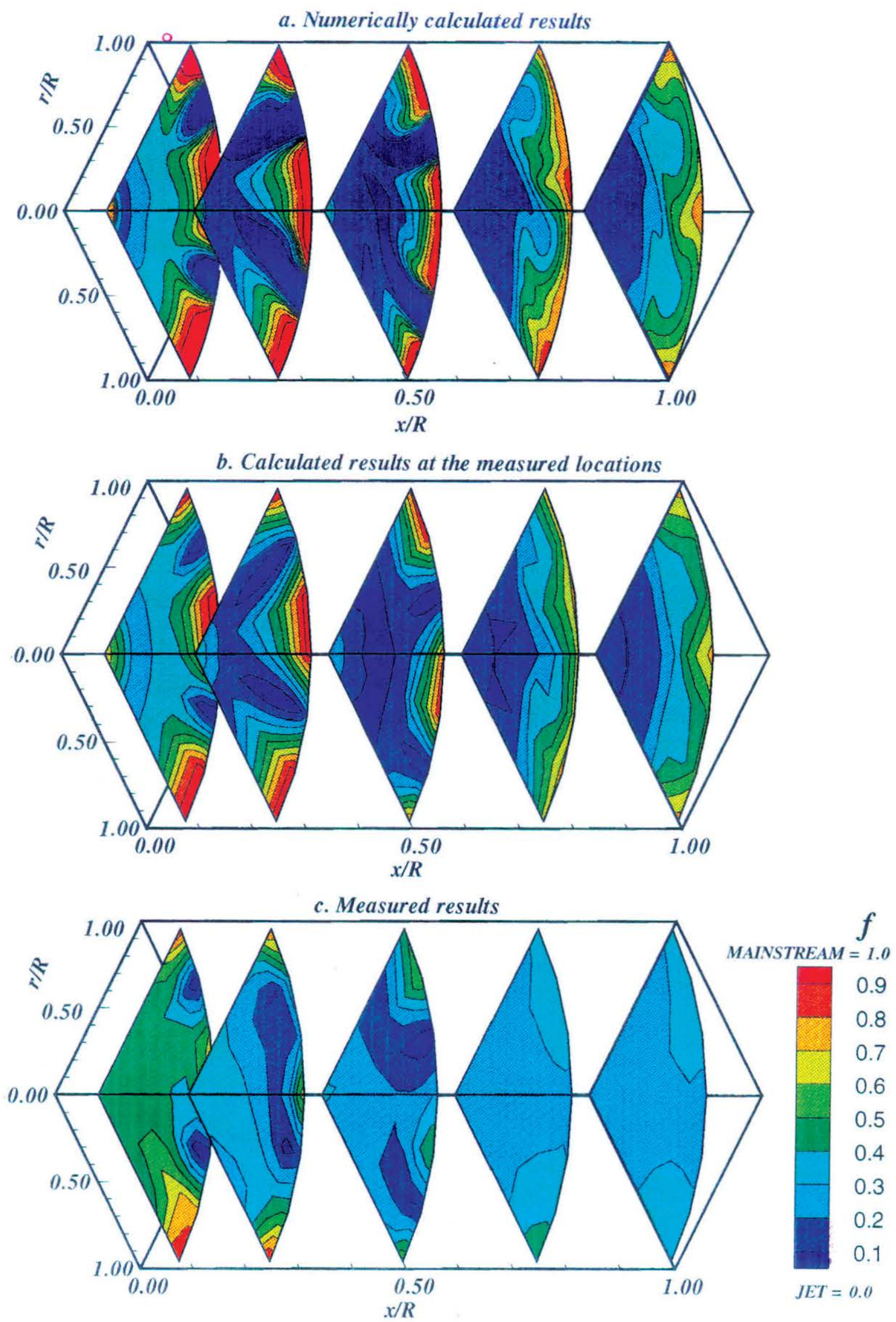

Figure-18. Comparison of the normalized temperature for the numerically calculated and measured results for configuration \#8, $J=53.2, M R=2.2, D R=1.26$, and $T_{e q}=0.313$ $22.5^{\circ}$ slot, $L / W=4,8$ orifices/row 

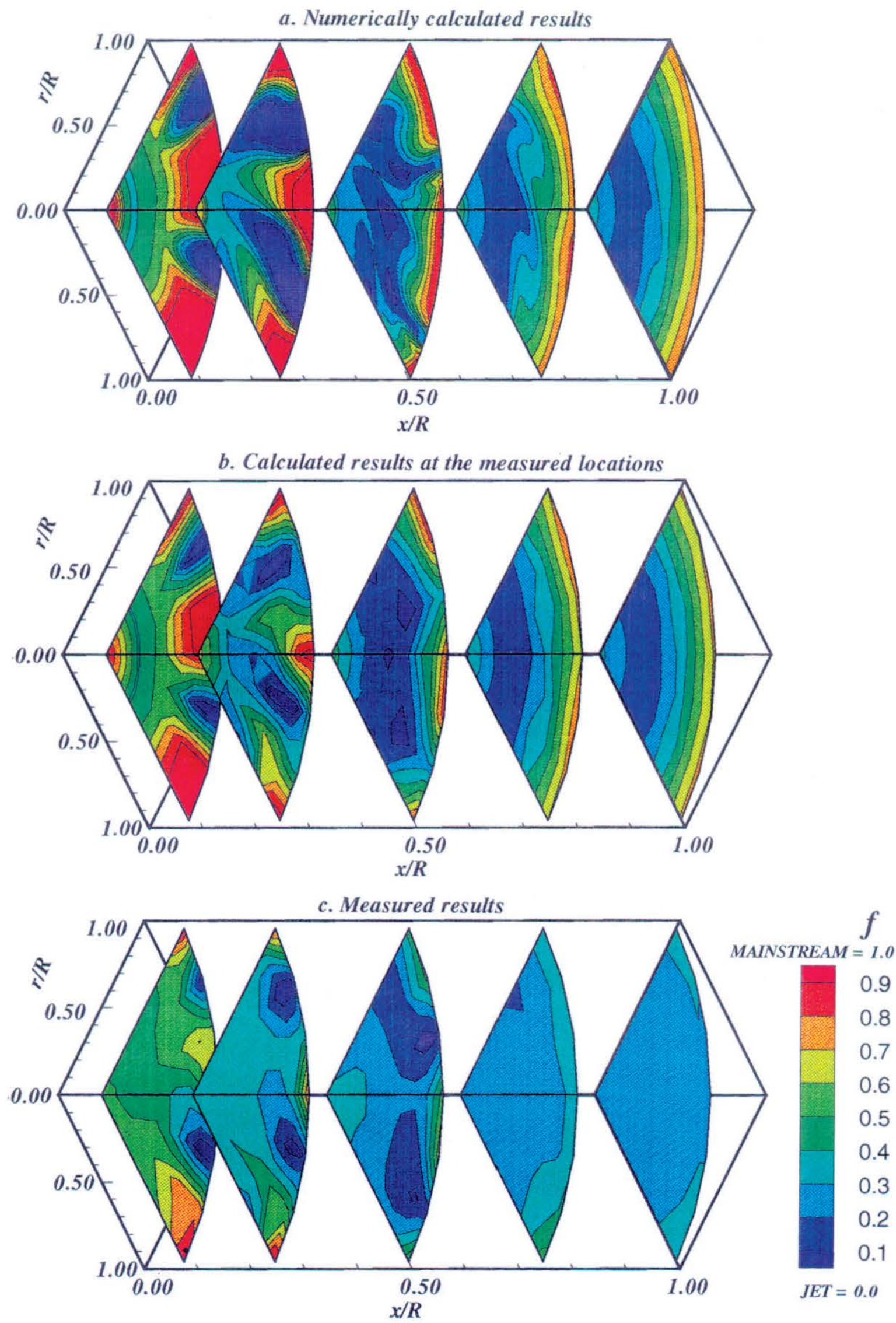

Figure-19. Comparison of the normalized temperature for the numerically calculated and measured results for configuration \# 9, $J=57.7, M R=2.2, D R=1.26$, and $T_{e q}=0.313$ $45^{\circ}$ slot, $L / W=4,8$ orifices/row 

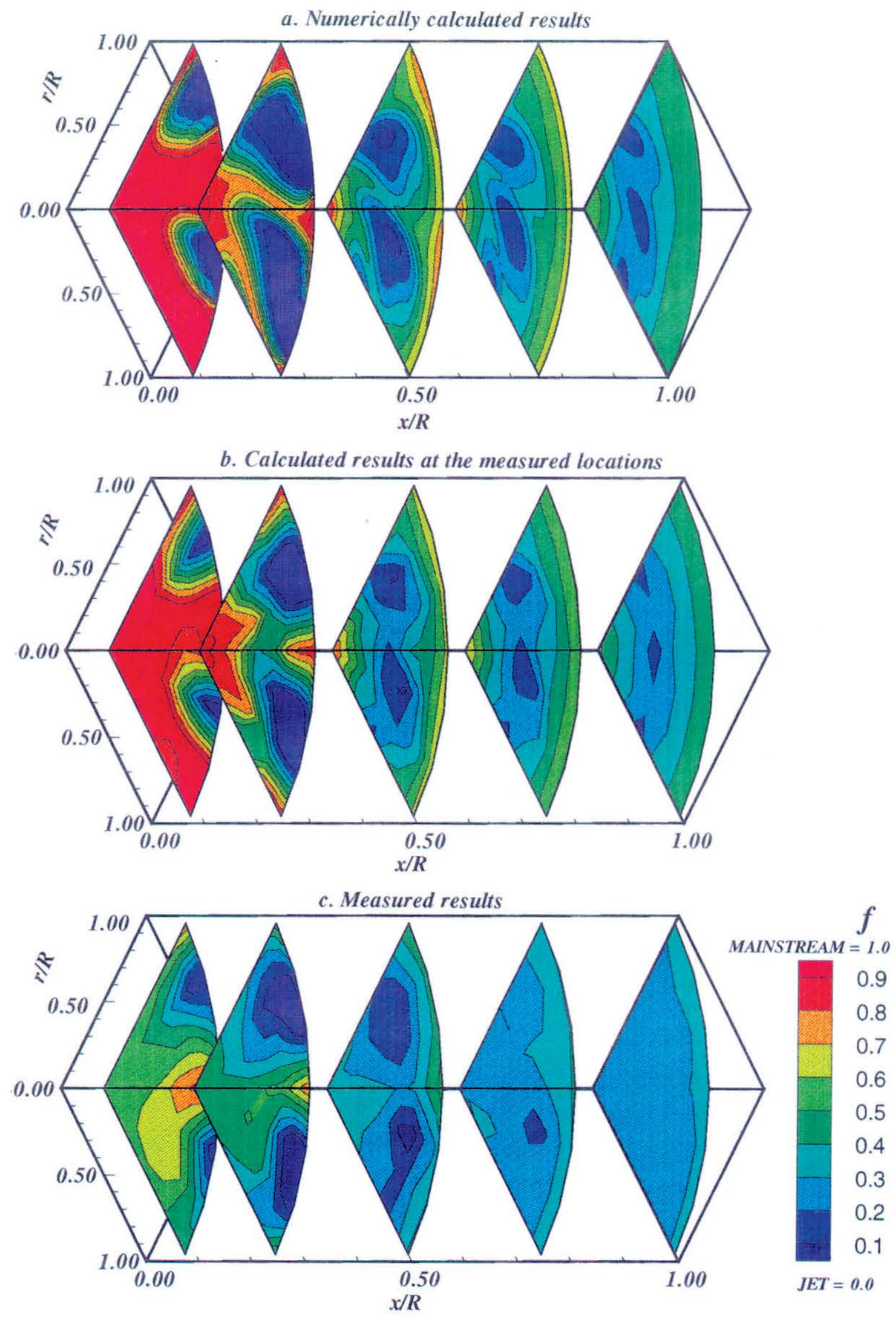

Figure-20. Comparison of the normalized temperature for the numerically calculated and measured results for configuration \# 10, $J=59.9, M R=2.2, D R=1.26$, and $T_{e q}=0.313$ $67.5^{\circ}$ slot, $L / W=4,8$ orifices/row 

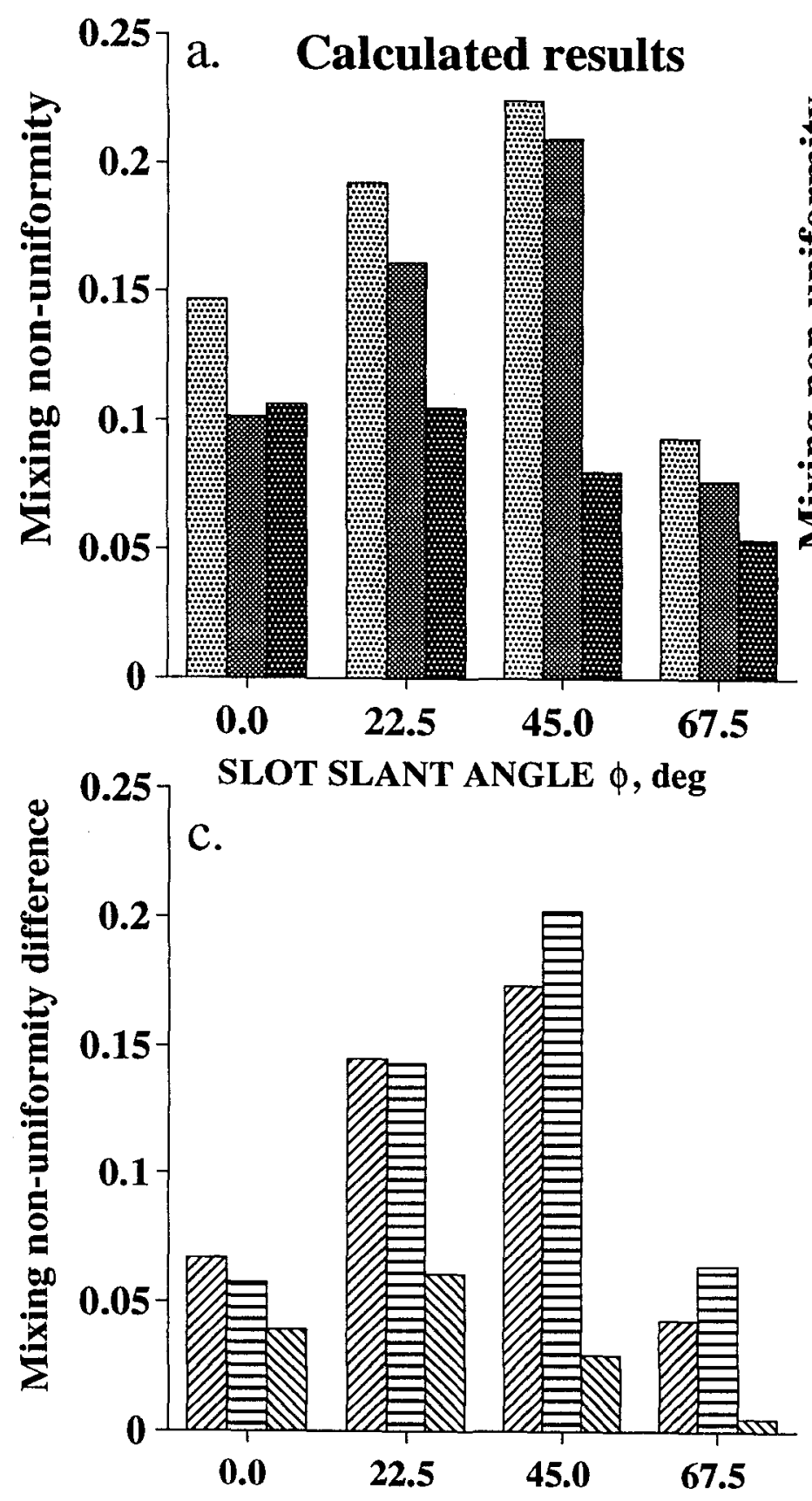

SLOT SLANT ANGLE $\phi$, deg

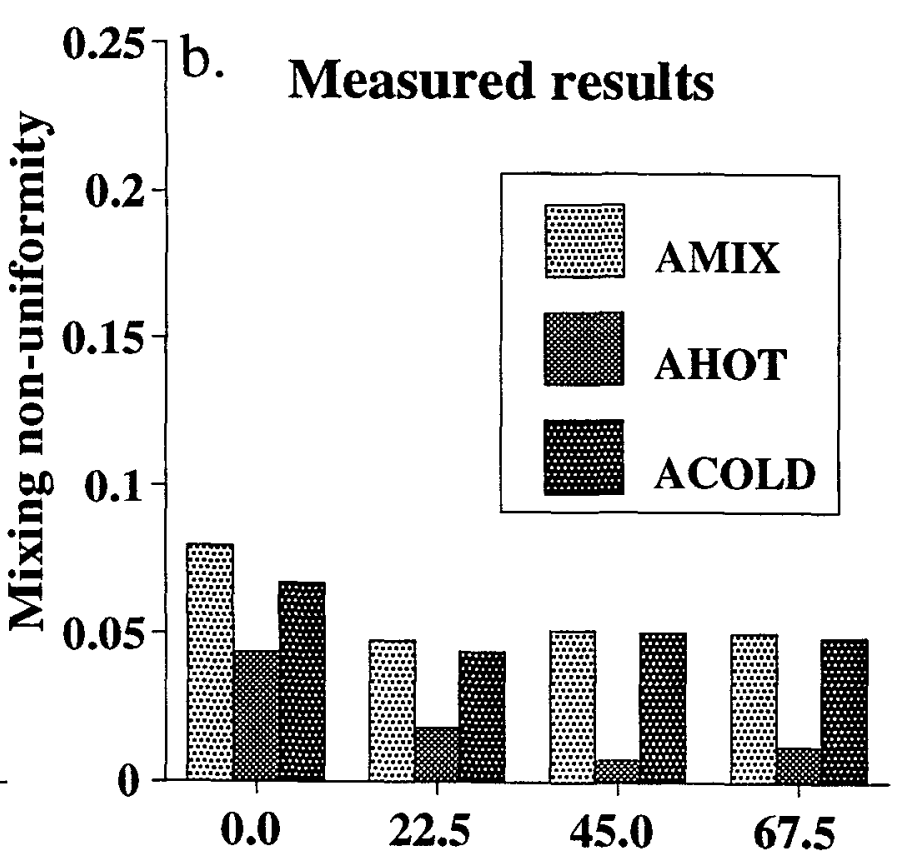

SLOT SLANT ANGLE $\phi$, deg
Q $\triangle \mathrm{AMIX}=\left|\mathbf{A M I X}_{\text {calc }} \cdot \mathbf{A M I X}_{\text {meas }}\right|$

$\equiv \Delta$ AHOT $=\mid$ AHOT $_{\text {calc }} \cdot$ AHOT $_{\text {meas }} \mid$

MU $\triangle A C O L D=\mid A_{\text {COLD }}$ calc $-A C O L D_{\text {meas }} \mid$

Note: The values plotted in are the differences in the statistical variances

between the predicted and measured values

Figure-21. Effect of slot slant angle $(\phi)$ on the difference between the calculated and measured results for the $\mathrm{L} / \mathrm{W}=4$ slots at $\mathrm{J}=52$ 


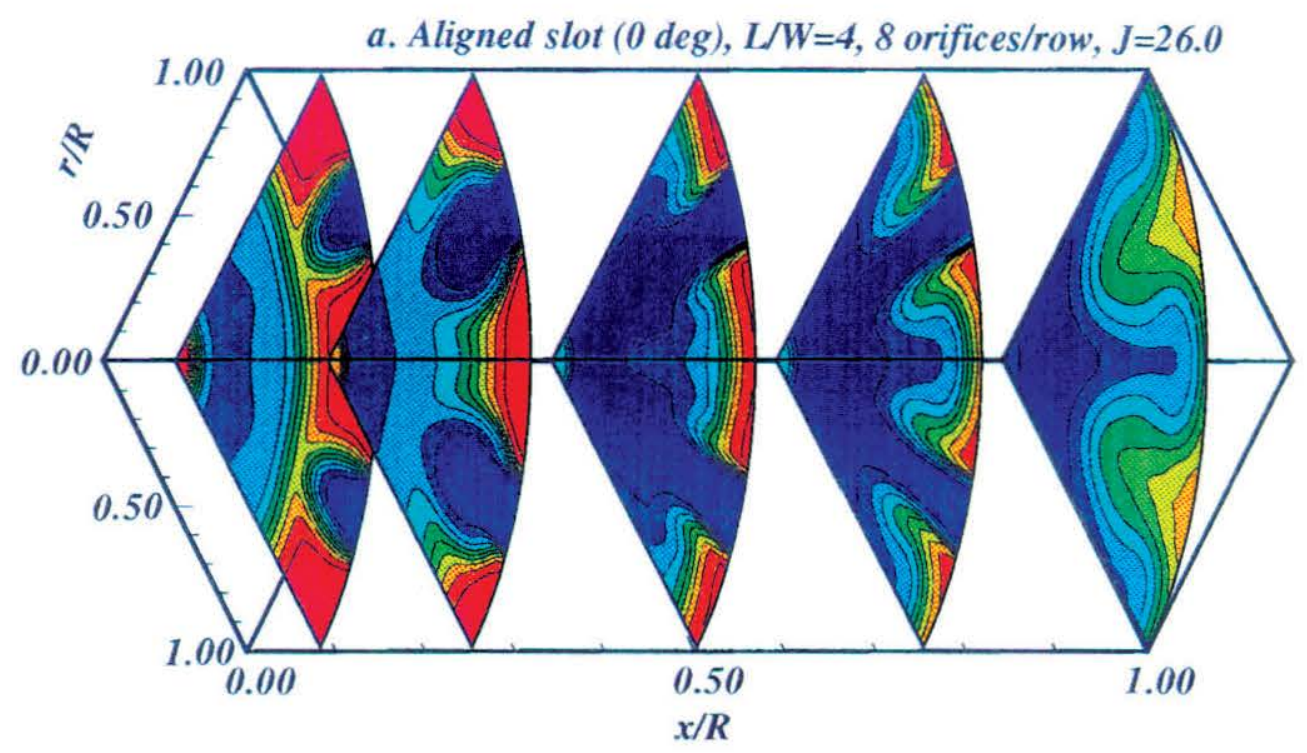

b. $22.5^{\circ}$ slot, $L / W=4,8$ orifices/row, $J=28.0$

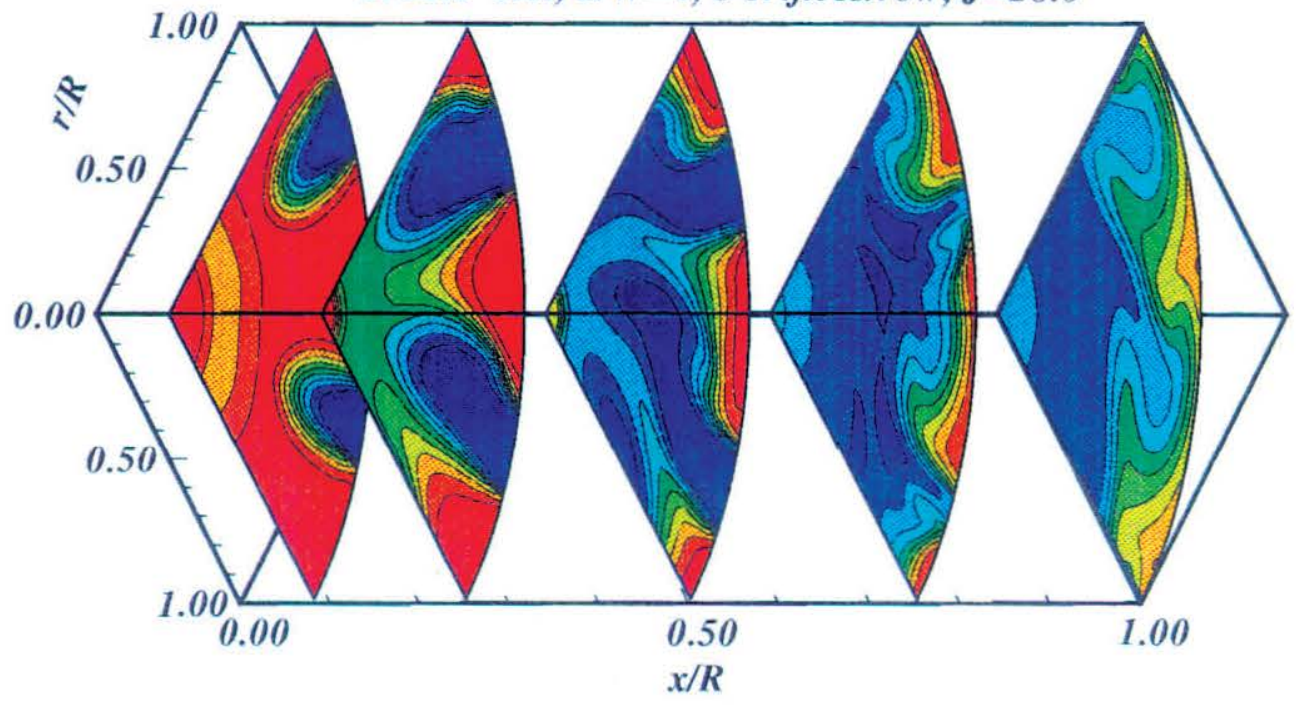

c. $45^{\circ}$ slot, $L / W=4,8$ orifices/row, $J=30.5$

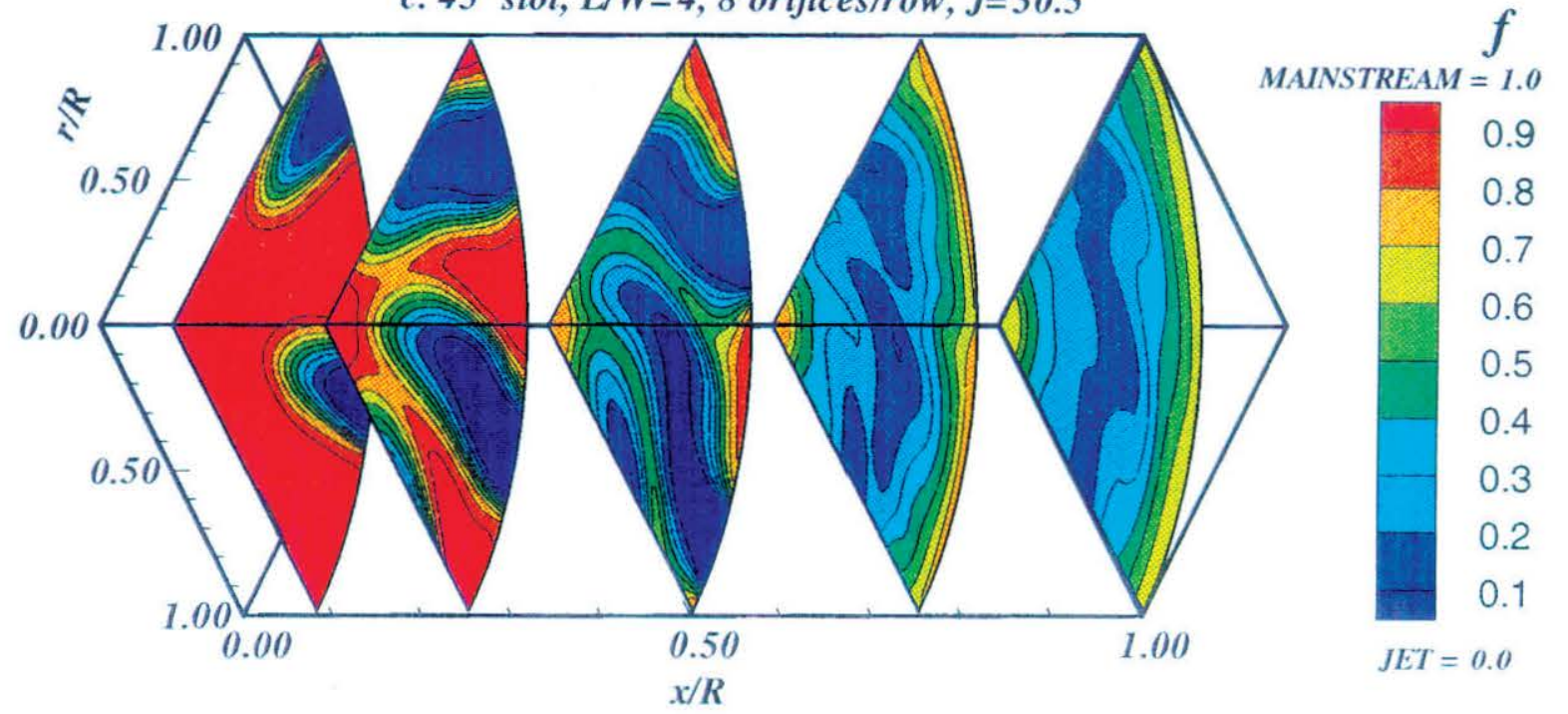

Figure-22. Normalized temperature distribution for the numerically calculated results for $M R=2.2, D R=1.26$, and $T_{e q}=0.313$ 

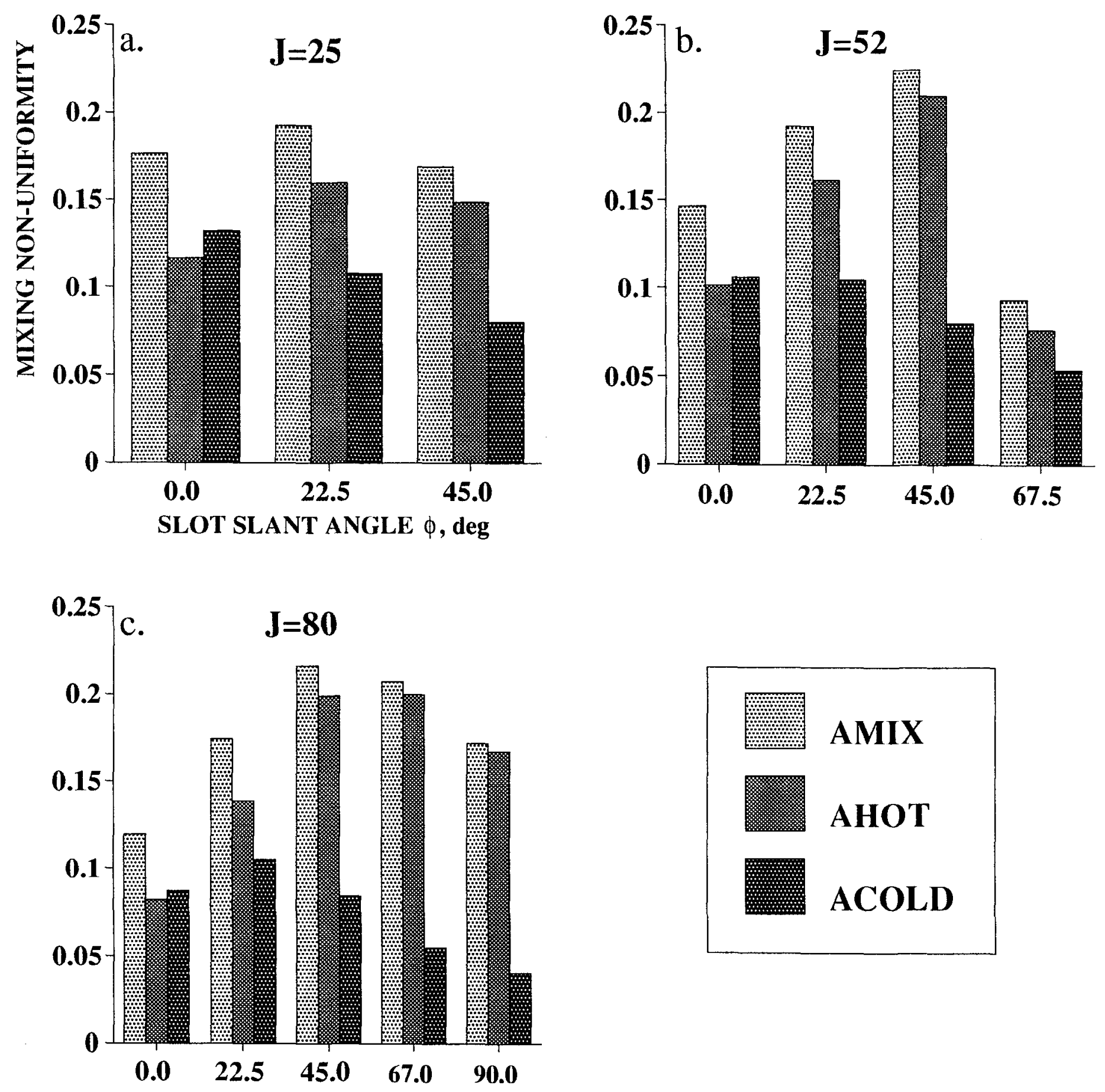

Figure-23. Effect of the slot slant angle $(\phi)$ on the numerically calculated mixing results for the $\mathrm{L} / \mathrm{W}=4$ slots. 

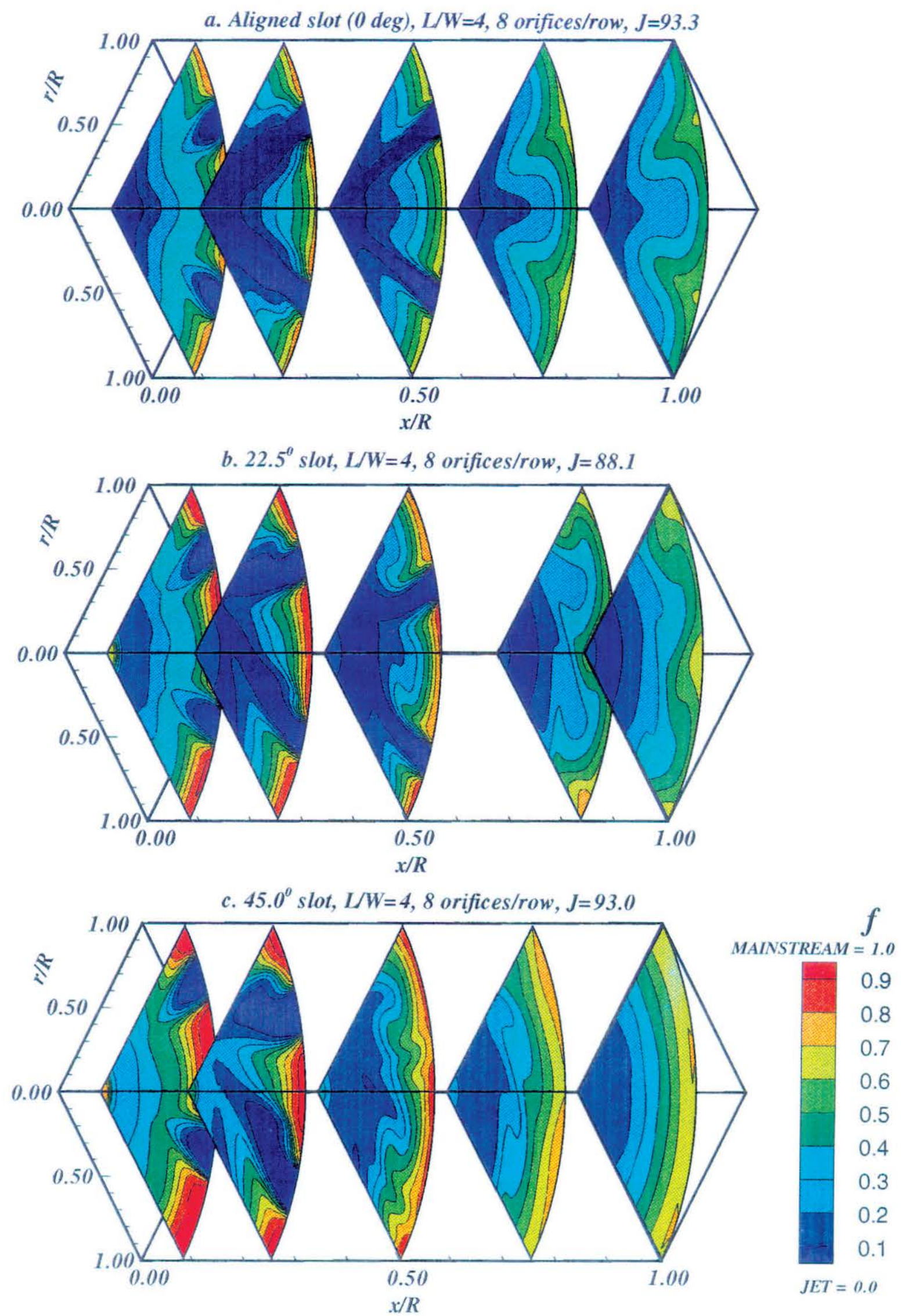

Figure-24. Normalized temperature distribution for the numerically calculated results for $M R=2.2, D R=1.26$, and $T_{e q}=0.313$ 

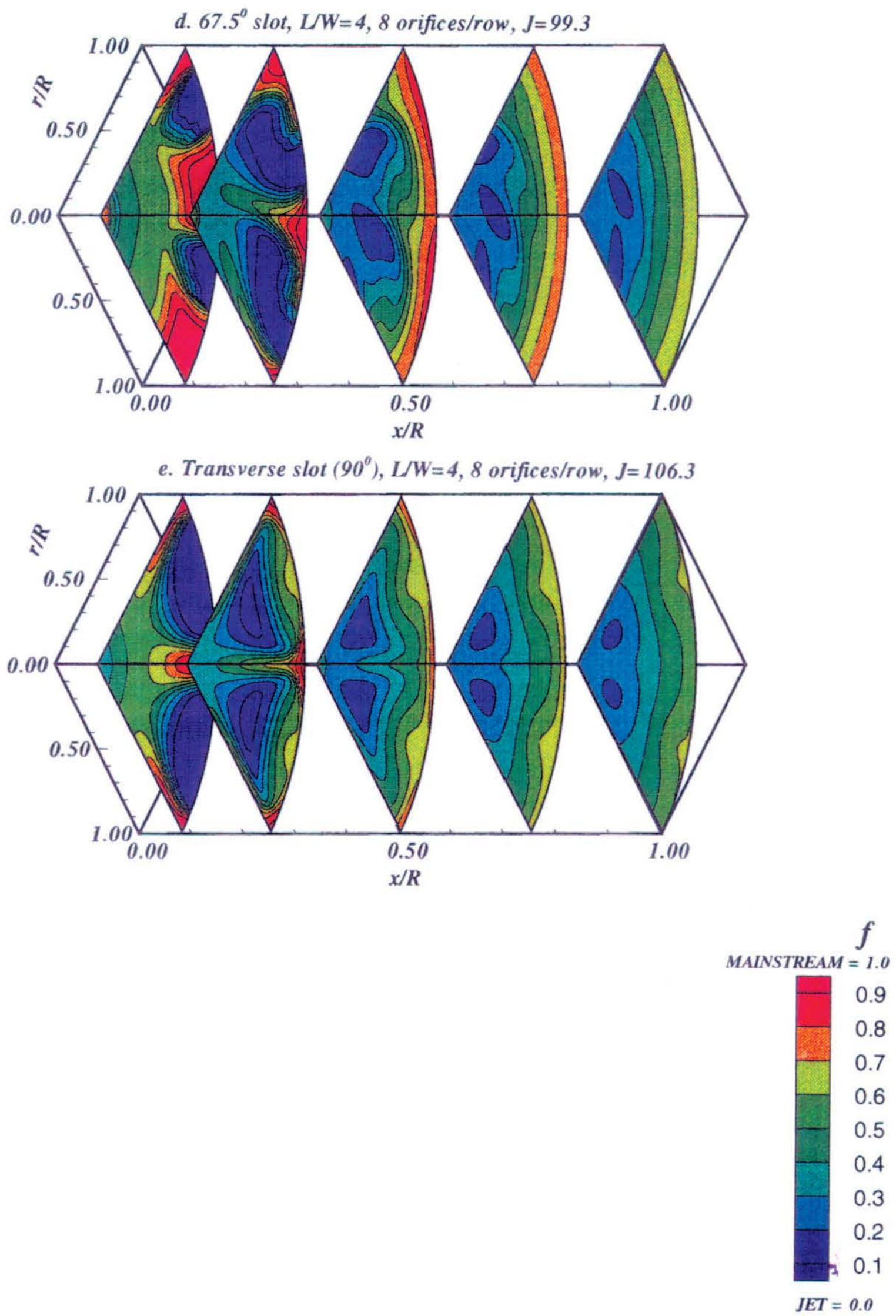

Figure-24 (continued) 

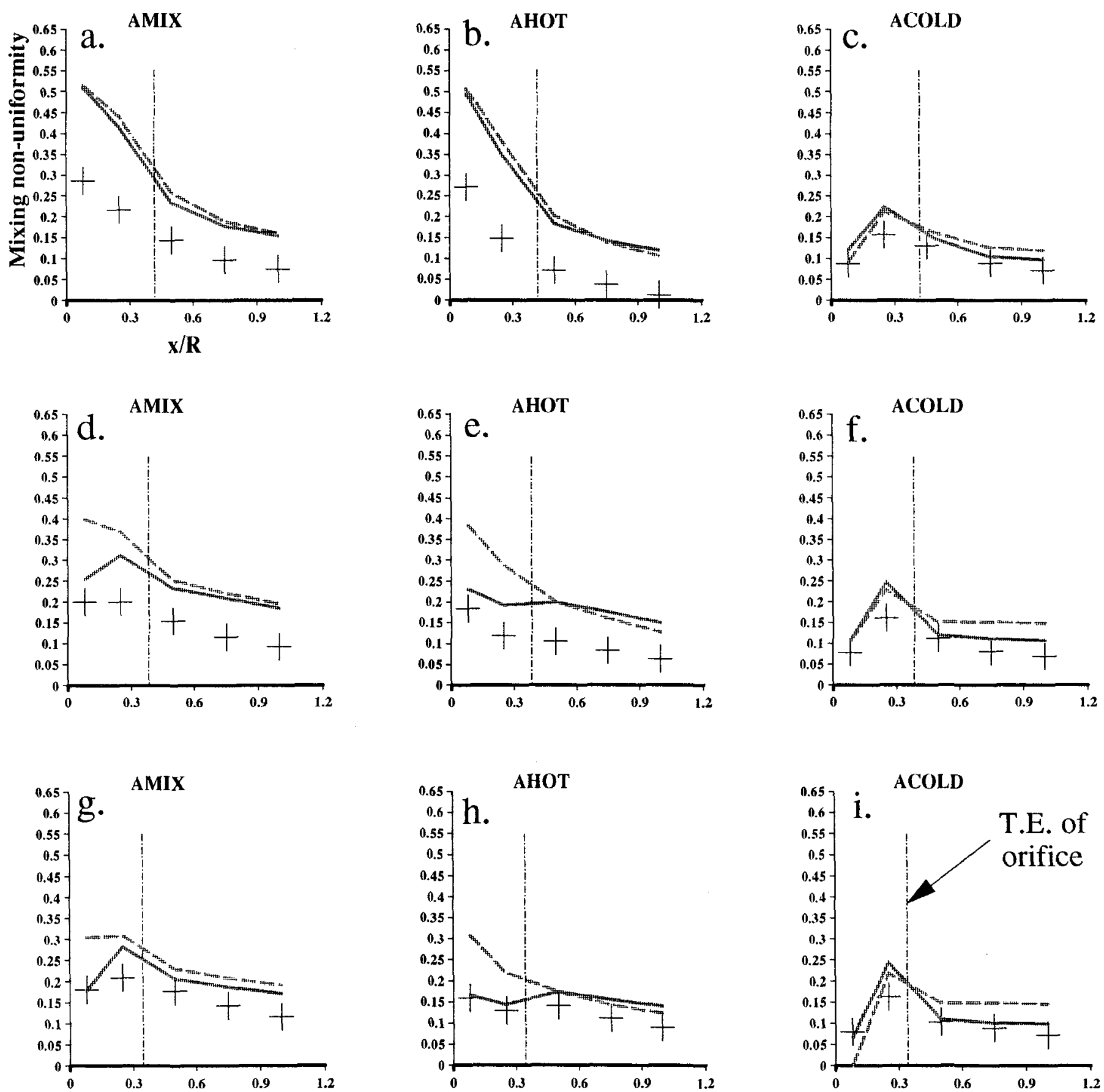

Conf \# 1, round holes, $\mathrm{J}=26.7, \mathrm{MR}=2.2, \mathrm{DR}=1.26(\mathrm{a}, \mathrm{b}, \mathrm{c})$

Conf \# 2 , round holes, $J=55.4, M R=2.2, D R=1.26(\mathrm{~d}, \mathrm{e}, \mathrm{f})$

Conf \# 3 , round holes, $\mathrm{J}=84.2, \mathrm{MR}=2.2, \mathrm{DR}=1.26(\mathrm{~g}, \mathrm{~h}, \mathrm{i})$

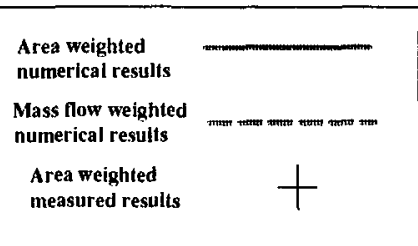

Figure-25. Comparison of the numerically calculated and measured results for round holes. 

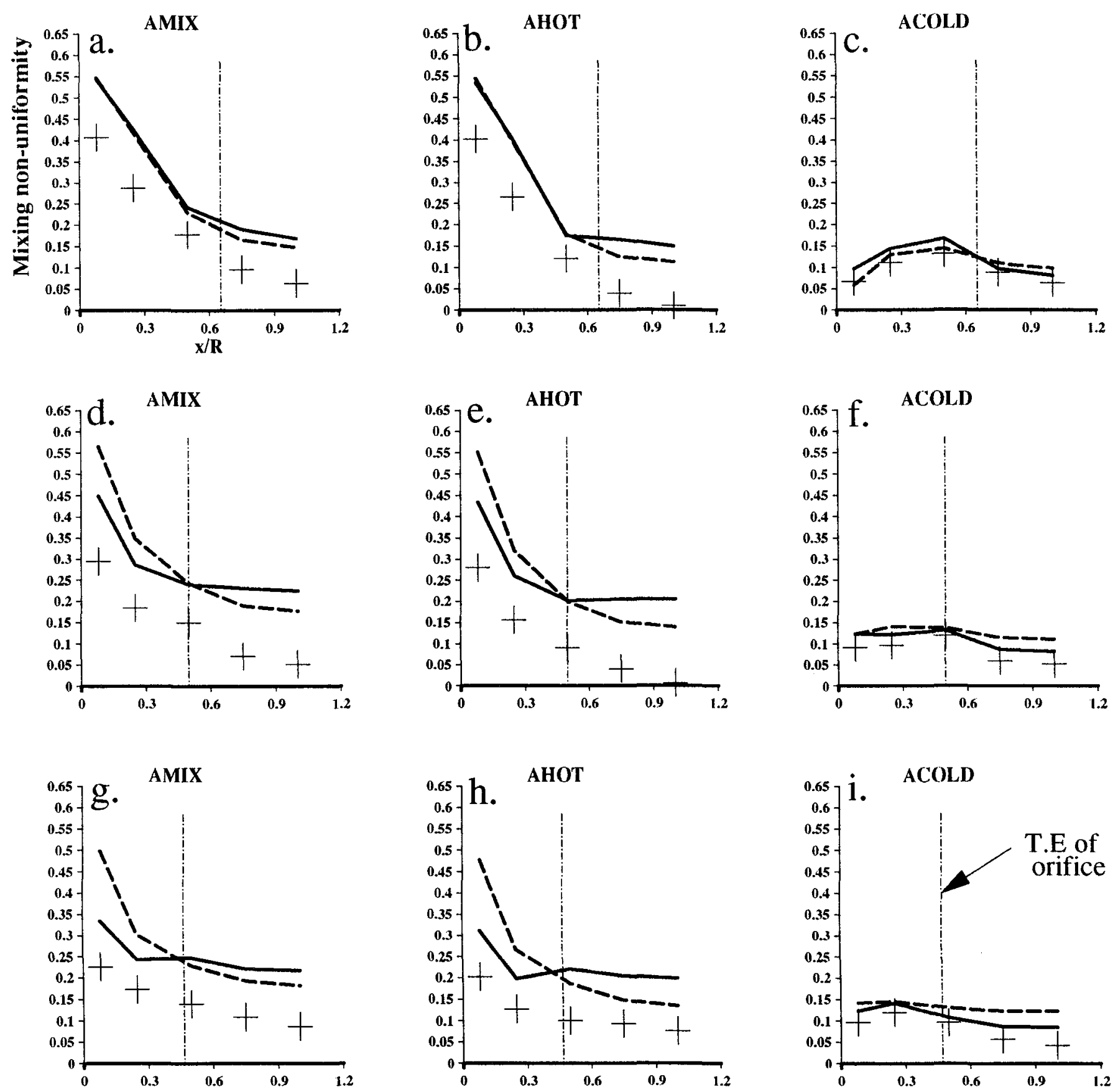

Conf \# 6, $45^{\circ}$ slot, $\mathrm{L} / \mathrm{W}=4, \mathrm{~J}=30.5, \mathrm{MR}=2.2, \mathrm{DR}=1.26,(\mathrm{a}, \mathrm{b}, \mathrm{c})$

Conf \# 9, $45^{\circ}$ slot, $\mathrm{L} / \mathrm{W}=4, \mathrm{~J}=57.7, \mathrm{MR}=2.2, \mathrm{DR}=1.26$, (d,e,f)

Conf \# 13, 45 ${ }^{\circ}$ slot, $\mathrm{L} / \mathrm{W}=4, \mathrm{~J}=93.0, \mathrm{MR}=2.2, \mathrm{DR}=1.26$, (g,h,i)

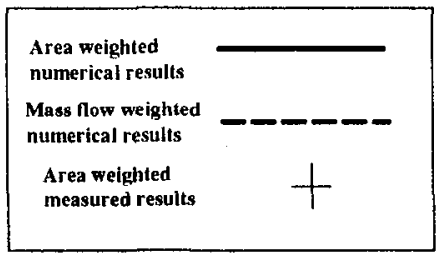

Figure-26. Comparison of the numerically calculated and measured results for the $45^{\circ}$ slanted slot, $\mathrm{L} / \mathrm{W}=4$. 

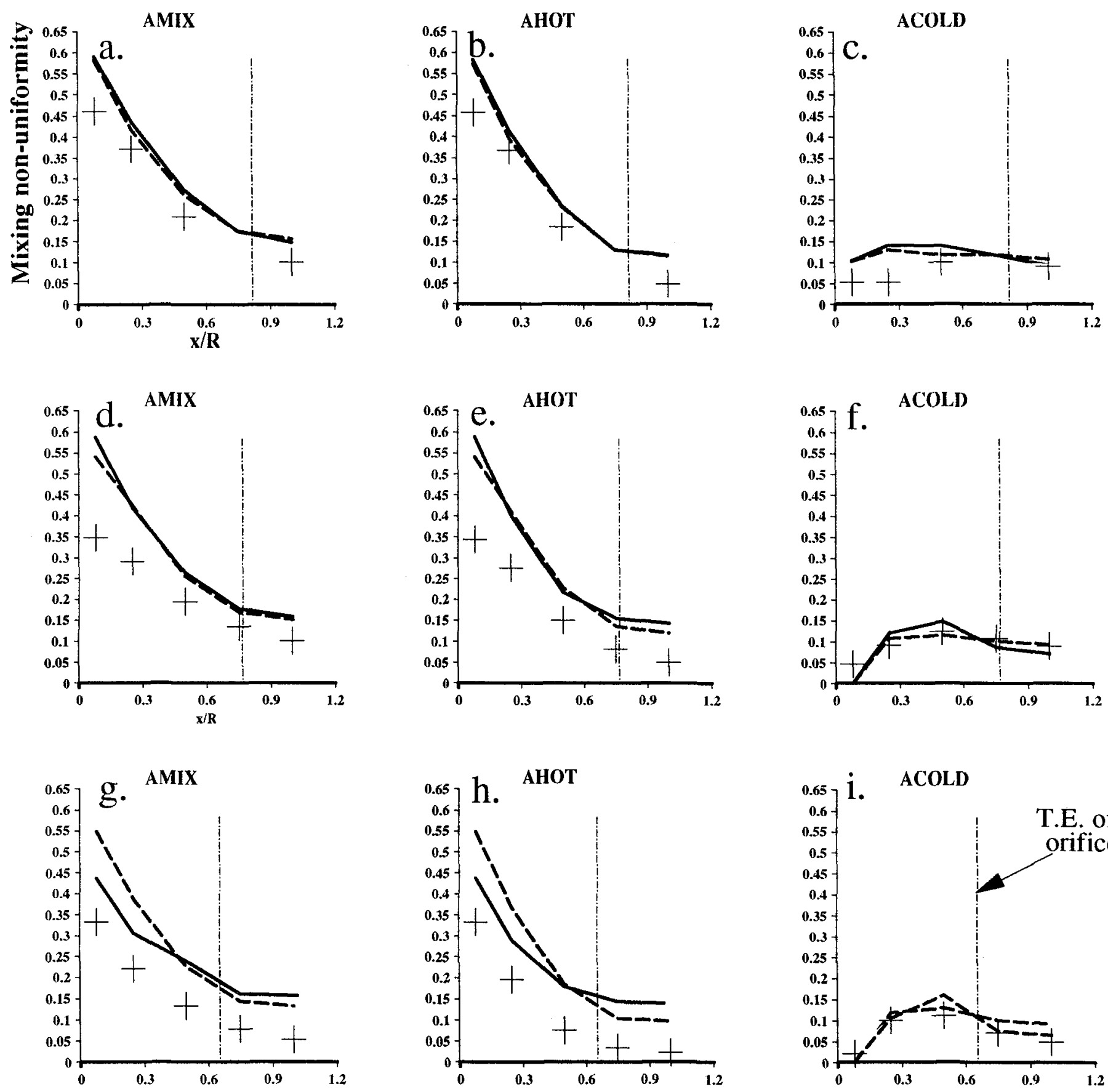

Conf \# 16, 45 $5^{\circ}$ slot, $\mathrm{L} / \mathrm{W}=8, \mathrm{~J}=28.1, \mathrm{MR}=2.2, \mathrm{DR}=1.26$, (a,b,c) Conf \# 17, 45 slot, $\mathrm{L} / \mathrm{W}=8, \mathrm{~J}=50.9, \mathrm{MR}=2.2, \mathrm{DR}=1.26$, (d,e,f) Conf \# 18, 45 ${ }^{\circ}$ slot, $\mathrm{L} / \mathrm{W}=8, \mathrm{~J}=88.5, \mathrm{MR}=2.2, \mathrm{DR}=1.26$, $(\mathrm{g}, \mathrm{h}, \mathrm{i})$
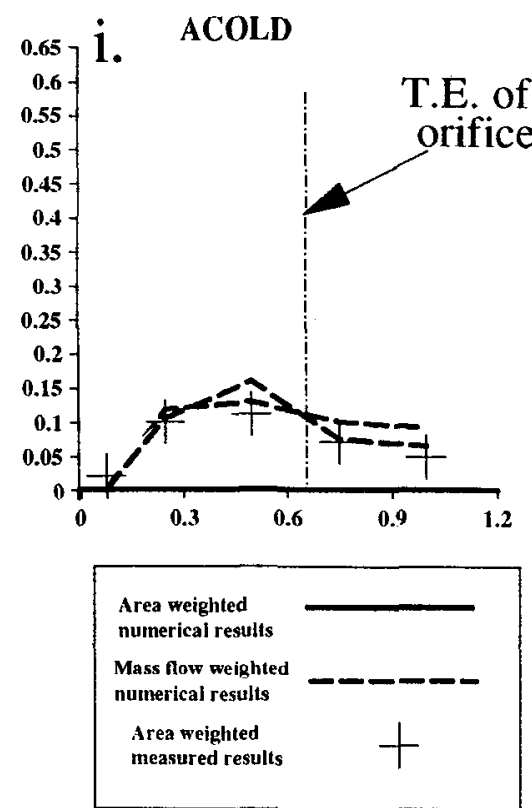

Figure-27. Comparison of the numerically calculated and measured results for the $45^{\circ}$ slanted slot, $\mathrm{L} / \mathrm{W}=8$. 

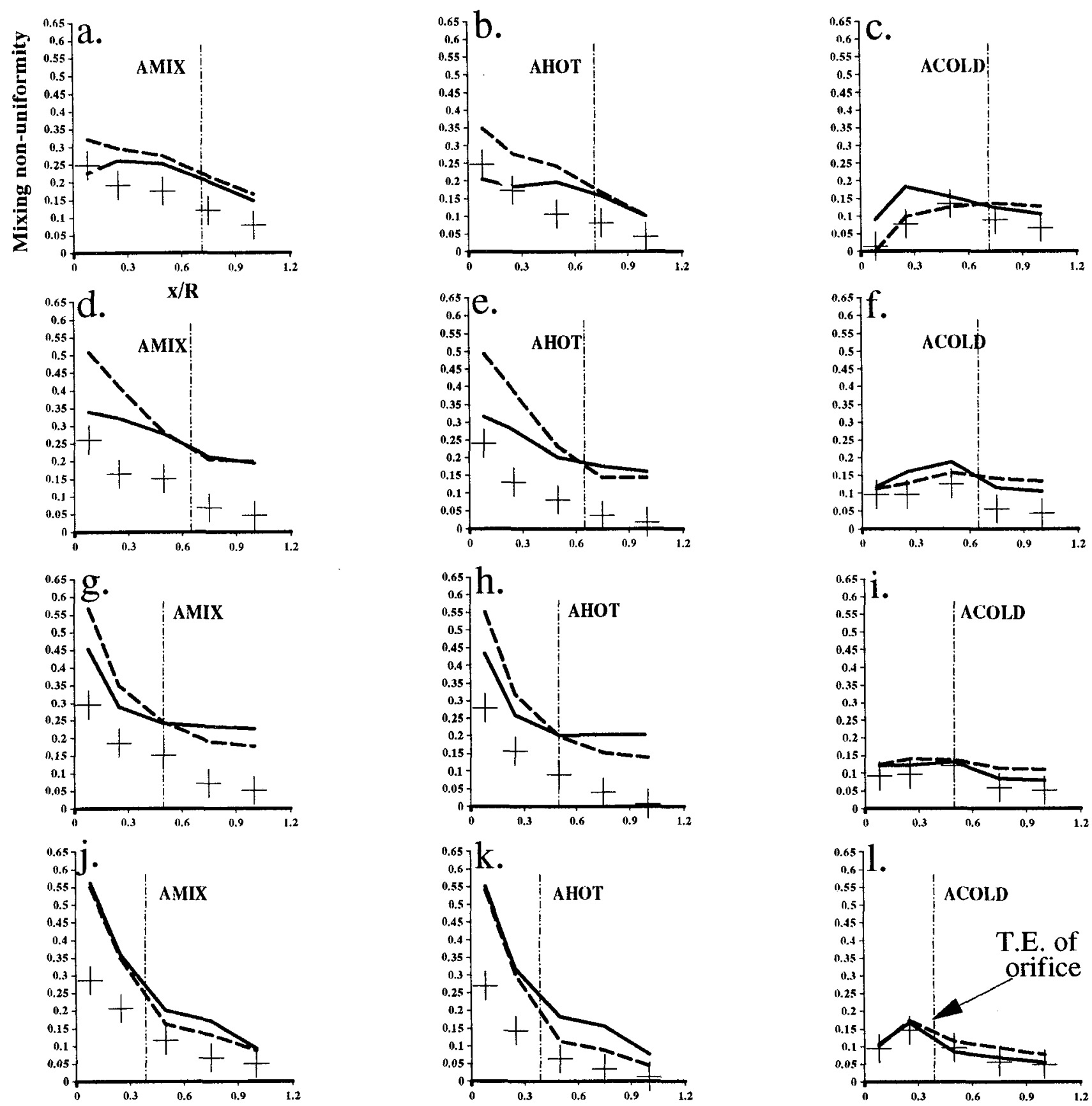

Conf \# 7, $0^{\circ}$ (aligned) slot, $\mathrm{L} / \mathrm{W}=4, \mathrm{~J}=51.1, \mathrm{MR}=2.2, \mathrm{DR}=1.26,(\mathrm{a}, \mathrm{b}, \mathrm{c})$ Conf \# 8, 22.5 slot, $\mathrm{L} / \mathrm{W}=4, \mathrm{~J}=53.2, \mathrm{MR}=2.2, \mathrm{DR}=1.26$, (d,e,f) Conf \# 9, 45 slot, $\mathrm{L} / \mathrm{W}=4, \mathrm{~J}=57.7, \mathrm{MR}=2.2, \mathrm{DR}=1.26$, (g,h,i) Conf \# 10, 67.5 slot, $\mathrm{L} / \mathrm{W}=4, \mathrm{~J}=59.9, \mathrm{MR}=2.2, \mathrm{DR}=1.26$, (g,h,i)

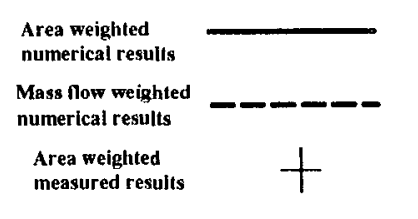

Figure-28. Comparison of the numerically calculated and measured results $\mathrm{L} / \mathrm{W}=4$ slots at a nominal momentum flux ratio $\mathrm{J}=52$. 
Public reporting burden for this collection of information is estimated to average 1 hour per response, including the time for reviewing instructions, searching existing data sources, gathering and maintaining the data needed, and completing and reviewing the collection of information. Send comments regarding this burden estimate or any other aspect of this collection of information, including suggestions for reducing this burden, to Washington Headquarters Services, Directorate for Information Operations and Reports, 1215 Jefferson Davis Highway, Suite 1204, Arlington, VA 22202-4302, and to the Office of Management and Budget, Paperwork Reduction Project (0704-0188), Washington, DC 20503.

\begin{tabular}{|l|l|l|}
\hline 1. AGENCY USE ONLY (Leave blank) & $\begin{array}{c}\text { 2. REPORT DATE } \\
\text { May } 1993\end{array}$ & $\begin{array}{r}\text { 3. REPORT TYPE AND DATES COVERED } \\
\text { Technical Memorandum }\end{array}$ \\
\hline
\end{tabular}

4. TITLE AND SUBTITLE

5. FUNDING NUMBERS

An Analytical Study of Dilution Jet Mixing in a Cylindrical Duct

6. AUTHOR(S)

WU-537-02-21-00

V.L. Oechsle, H.C. Mongia, and J.D. Holdeman

7. PERFORMING ORGANIZATION NAME(S) AND ADDRESS(ES)

National Aeronautics and Space Administration

Lewis Research Center

Cleveland, Ohio 44135-3191

8. PERFORMING ORGANIZATION

REPORT NUMBER

E-7887

9. SPONSORING/MONITORING AGENCY NAME(S) AND ADDRESS(ES)

National Aeronautics and Space Administration

Washington, DC 20546-0001

10. SPONSORING/MONITORING

AGENCY REPORT NUMBER

NASA TM-106181

AIAA-93-2043

11. SUPPLEMENTARY NOTES

Prepared for the 29th Joint Propulsion Conference and Exhibit cosponsored by the AIAA, SAE, ASME, and ASEE Monterey, California, June 28-30, 1993. V.L. Oechsle and H.C. Mongia, Allison Gas Turbine Division, General Motors Corporation, Indianapolis, Indiana 46206; and J.D. Holdeman, NASA Lewis Research Center. Responsible person, J.D. Holdeman, (216) 433-5846.

12a. DISTRIBUTION/AVAILABILITY STATEMENT

12b. DISTRIBUTION CODE

Unclassified - Unlimited

Subject Category: 07

Available electronically at http://gltrs.grc.nasa.gov/GLTRS

This publication is available from the NASA Center for AeroSpace Information, (301) 621-0390.

13. ABSTRACT (Maximum 200 words)

The mixing performance in a mixing section of a rich burn/quick mix/lean burn (RQL) combustor has been calculated using a 3-D numerical model in a non-reacting environment. The numerically calculated results have been compared with the measured data reported by Hatch, Sowa, Samuelsen, and Holdeman, 1992. The numerical 3-D temperature fields qualitatively agree with the experimental data. Also the development of the mixing flow and temperature non-uniformity trends throughout the mixing section for the numerically calculated results quantitatively agree with the measured data. The numerical model predicts less mixing and enhances the temperature gradients as compared to the measured data for the cases reported by Hatch et al. (1992) which include circular and slot orifice shapes (with different slant angles and aspect ratios). The predicted and measured results generally agree in the selection of the slanted slot orifice configuration yielding the best overall mixing performance (based on temperature uniformity) of all the configurations analyzed herein.

14. SUBJECT TERMS

Dilution; Jet mixing flow; Gas turbine; Combustion chamber; Emissions

17. SECURITY CLASSIFICATION OF REPORT

Unclassified
18. SECURITY CLASSIFICATION OF THIS PAGE

Unclassified
19. SECURITY CLASSIFICATION OF ABSTRACT

Unclassified
60

15. NUMBER OF PAGES

16. PRICE CODE

A04

20. LIMITATION OF ABSTRACT

Standard Form 298 (Rev. 2-89)

Prescribed by ANSI Std. Z39-18 298-102 